\title{
Chemical composition of ambient aerosol, ice residues and cloud droplet residues in mixed-phase clouds: single particle analysis during the Cloud and Aerosol Characterization Experiment (CLACE 6)
}

\author{
M. Kamphus ${ }^{1, *}$, M. Ettner-Mahl, ${ }^{2, *}$, T. Klimach ${ }^{2}$, F. Drewnick ${ }^{2}$, L. Keller ${ }^{3}$, D. J. Cziczo ${ }^{3, * * *}$, S. Mertes ${ }^{4}$, \\ S. Borrmann ${ }^{1,2}$, and J. Curtius ${ }^{1, * * *}$ \\ ${ }^{1}$ Institute for Atmospheric Physics, Johannes Gutenberg University, Mainz, Germany \\ ${ }^{2}$ Max Planck Institute for Chemistry, Mainz, Germany \\ ${ }^{3}$ Institute for Atmospheric and Climate Science, ETH Zurich, Zurich, Switzerland \\ ${ }^{4}$ Leibniz Institute for Tropospheric Research, Leipzig, Germany \\ *now at: Emerson Process Management GmbH \& Co OHG, Hasselroth, Germany \\ ** now at: Boehringer Ingelheim Pharma GmbH \& Co KG, Ingelheim am Rhein, Germany \\ **** now at: Atmospheric Science \& Global Change Division, Pacific Northwest National Laboratory, Richland, WA, USA \\ ***** now at: Institute for Atmospheric and Environmental Sciences, Goethe-University Frankfurt, \\ Frankfurt am Main, Germany
}

Received: 30 June 2009 - Published in Atmos. Chem. Phys. Discuss.: 17 July 2009

Revised: 30 July 2010 - Accepted: 12 August 2010 - Published: 30 August 2010

\begin{abstract}
Two different single particle mass spectrometers were operated in parallel at the Swiss High Alpine Research Station Jungfraujoch (JFJ, $3580 \mathrm{~m}$ a.s.l.) during the Cloud and Aerosol Characterization Experiment (CLACE 6) in February and March 2007. During mixed phase cloud events ice crystals from 5-20 $\mu \mathrm{m}$ were separated from larger ice aggregates, non-activated, interstitial aerosol particles and supercooled droplets using an Ice-Counterflow Virtual Impactor (Ice-CVI). During one cloud period supercooled droplets were additionally sampled and analyzed by changing the Ice-CVI setup. The small ice particles and droplets were evaporated by injection into dry air inside the IceCVI. The resulting ice and droplet residues (IR and DR) were analyzed for size and composition by the two single particle mass spectrometers: a custom-built Single Particle Laser-Ablation Time-of-Flight Mass Spectrometer (SPLAT) and a commercial Aerosol Time-of-Flight Mass Spectrometer (ATOFMS, TSI Model 3800). During CLACE 6 the SPLAT instrument characterized 355 individual IR that produced a mass spectrum for at least one polarity and the ATOFMS measured 152 IR. The mass spectra were binned
\end{abstract}

Correspondence to: J. Curtius

(curtius@iau.uni-frankfurt.de) in classes, based on the combination of dominating substances, such as mineral dust, sulfate, potassium and elemental carbon or organic material. The derived chemical information from the ice residues is compared to the JFJ ambient aerosol that was sampled while the measurement station was out of clouds (several thousand particles analyzed by SPLAT and ATOFMS) and to the composition of the residues of supercooled cloud droplets (SPLAT: 162 cloud droplet residues analyzed, ATOFMS: 1094). The measurements showed that mineral dust was strongly enhanced in the ice particle residues. Close to all of the SPLAT spectra from ice residues did contain signatures from mineral compounds, albeit connected with varying amounts of soluble compounds. Similarly, close to all of the ATOFMS IR spectra show a mineral or metallic component. Pure sulfate and nitrate containing particles were depleted in the ice residues. Sulfate and nitrate was found to dominate the droplet residues ( $~ 90 \%$ of the particles). The results from the two different single particle mass spectrometers were generally in agreement. Differences in the results originate from several causes, such as the different wavelength of the desorption and ionisation lasers and different size-dependent particle detection efficiencies.

Published by Copernicus Publications on behalf of the European Geosciences Union. 


\section{Introduction}

In the atmosphere, freezing of water can occur homogeneously or heterogeneously. The homogeneous process is the spontaneous formation of ice within a liquid droplet and requires temperatures of $<-37^{\circ} \mathrm{C}$ and saturation near that of liquid water (Koop et al., 2000). The heterogeneous process requires the presence of an ice nucleus (IN) which allows ice phase formation starting at temperatures already slightly below $0{ }^{\circ} \mathrm{C}$ for some types of IN (Vali, 2008; Szyrmer and Zawadzki, 1997). Heterogeneous ice nucleation in clouds with supercooled water results in subsequent efficient growth of the ice crystals due to the Bergeron-Findeisen process. This represents the main initiation process of precipitation at midlatitudes (Pruppacher and Klett, 1997; Lau and Wu, 2003).

For a better understanding of ice formation in mixed-phase clouds, for improved forecasting of precipitation and for estimating the anthropogenic influence on these processes it is important to know how the chemical composition of an aerosol particle influences its ability to act as an IN. Cantrell and Heymsfield (2005) describe the current understanding of the production of ice in tropospheric clouds. While significant progress in understanding homogeneous nucleation and secondary ice production has been made, much less is known about heterogeneous nucleation. Some important sources of ice nuclei have been identified, but there is still a lack of a theoretical framework and open questions exist concerning the physical and chemical properties of the IN and, in particular, the question of anthropogenic influence. Also, the state of mixing of the IN and the influence of possible coatings on ice nucleation require detailed further analysis.

For primary ice production there are several heterogeneous pathways of freezing: deposition, condensation, immersion, contact and evaporation freezing (Pruppacher and Klett, 1997; Durant and Shaw, 2005). To investigate the heterogeneous freezing process for some of these pathways in the laboratory, aerosol particles are introduced in an environment with defined temperatures and supersaturations, for example, in continuous flow diffusion chambers (CFDC, Rogers et al., 2001; Bundke et al., 2008; Stetzer et al., 2008). Salam et al. (2006) investigated the ice nucleation efficiency for kaolinite and montmorillonite in deposition/condensation nucleation. Both mineral dust samples acted as very efficient IN but no activity in the deposition mode for kaolinite above $-22^{\circ} \mathrm{C}$ and for montmorillonite above $-15^{\circ} \mathrm{C}$ were observed. For immersion freezing, similar results were obtained by Ettner et al. (2004) for sulfuric acid solution droplets of various concentrations containing kaolinite, montmorillonite and graphite as IN. Field et al. (2006) investigated the ice nucleating ability of desert dust particles from the Asian and Saharan desert in the AIDA (Aerosol Interactions and Dynamics in the Atmosphere) chamber. The activated fraction of dust particles forming ice was $5-10 \%$ at $-20^{\circ} \mathrm{C}$.
In the ice nucleation studies described in the previous section aerosol particles with known composition, size and origin were introduced into ice chambers. The nature of ambient IN cannot be investigated as easily with chamber experiments due to the low, $\sim 10$ 's per liter, number density of IN in the atmosphere (DeMott et al., 2003). To analyze the chemical composition and ice nucleating ability of ambient aerosol, several field studies have applied a CFDC in combination with mass spectrometric analysis, mainly on single particle basis (DeMott et al., 2003). A CVI (counterflow virtual impactor) was used between the CFDC and the PALMS (Particle Analysis by Laser Mass Spectrometry) instrument to evaporate condensed phase water from the IN before chemical analysis (Cziczo et al., 2003). During the INSPECT (Ice Nuclei Spectroscopy) campaigns this combination was operated at the Storm Peak Laboratory, CO, USA, at $3220 \mathrm{~m}$ a.s.l. (Cziczo et al., 2003, DeMott et al., 2003; Richardson et al., 2007). It is reported that IN which formed in the CFDC were dominated by $\mathrm{Si}$ and $\mathrm{SiO}$. A classification of all INSPECT ice nuclei spectra (Cziczo et al., 2006) identified mineral dust and fly ash as the predominant species, but also metallic compounds, sulfate, organics and potassium were found.

Recently, studies by Prenni et al. (2009) and Pratt et al. (2009) highlighted the potential role of biological particles for atmospheric ice nucleation. Single particle mass spectrometry was used by Pratt et al. to reveal that biological particles accounted for $\sim 33 \%$ of the ice residues measured in clouds during the fall season at $\sim 8.0 \mathrm{~km}$ altitude. The freezing behaviour of primary biological aerosol particles has also been studied with supercooled water droplets in the Mainz Vertical Wind Tunnel facility (von Blohn et al., 2005). A detailed discussion about the role of biological particles in cloud physics is given by Möhler et al. (2007).

The experiments presented in the previous paragraphs investigated the nucleation of ambient aerosol or individual substances in a controlled environment (with given temperature and RH) such as the CFDC or an aerosol chamber like AIDA. There are only a few experiments to date which investigated the chemical composition of ice nuclei in naturally formed ice particles. Collecting ice crystal residues behind a CVI with in-situ mass spectrometric analysis or with subsequent analysis in the laboratory has been one method. Cziczo et al. (2004) used a combination of a CVI and the PALMS instrument onboard an aircraft to chemically analyze anvil cirrus IN. Ions of sulfate, potassium, organics and nitrogen monoxide dominated the spectra outside clouds (95\%) and in the interstitial aerosol $(88 \%)$ whereas cirrus IN were mainly composed of mineral dust or fly ash (44\%). Targino et al. (2006) presented a study of ice crystal residues collected behind a CVI onboard a research aircraft. Their cluster analysis of 609 particles showed 58\% mineral dust (aluminosilicates, $\mathrm{Fe}$ and $\mathrm{Si}$ rich), $23 \%$ low $\mathrm{Z}$ particles (presumably organic material) and sea salt $6.7 \%$. Sulfur was detected across all groups, indicating aging and in-cloud processing. 
To date, cirrus clouds were the only ice-containing clouds for which ice residues were chemically analyzed in the natural environment. In contrast, it was not possible to separate the ice particles from supercooled cloud droplets in mixed phase clouds. With a newly designed Ice-CVI (Mertes et al., 2007), it is possible to separate small ice crystals from supercooled cloud droplets thus enabling in-situ analysis of the ice residues. A suitable site for such measurements is the High Alpine Research Station Jungfraujoch located in the Swiss Alps which is frequently exposed to mixed phase clouds during winter with $37 \%$ average cloud coverage (Cozic et al., 2007).

In order to characterize the ice residues, single particle laser ablation mass spectrometry was utilized during the CLACE 6 campaign. The chemical compounds within a single particle are vaporized and ionized with one laser pulse. In contrast to mass spectrometers, which use thermal evaporation at temperatures $<1000^{\circ} \mathrm{C}$ such as the AMS (Canagaratna et al., 2007), even refractory material like mineral dust particles, which are likely to be important IN, can be analyzed. The limitation of this technique is that it is not quantitative because the process of laser ablation is not understood in detail for complex aerosol particles (Schoolcraft et al., 2000). Nevertheless, the importance of different chemical compounds for heterogeneous ice nucleation can be estimated by classifying the ice residue particles into different chemical groups and comparing them to the background aerosol.

Single particle mass spectrometry for ambient aerosol particles (but no ice or droplet residues) has been performed previously at the Jungfraujoch research station by Hinz et al. (2005).

\section{Experimental}

\subsection{Sphinx laboratory at the Jungfraujoch}

The Sphinx laboratory is situated at $3580 \mathrm{~m}$ a.s.l. at the Jungfraujoch (JFJ) in the Swiss Alps at $7^{\circ} 59^{\prime} 2^{\prime \prime} \mathrm{E}, 46^{\circ}$ $32^{\prime} 53^{\prime \prime} \mathrm{N}$. During the winter months it is located in the free troposphere without regular injections from the planetary boundary layer (Coen et al., 2007) and it is frequently surrounded by mixed-phase clouds. The intensive measurement period of the Cloud and Aerosol Characterization Experiment 6 (CLACE 6) took place from 17 February to 14 March 2007. During that time almost exclusively westerly or northwesterly flow conditions were present. There were no indications of Saharan dust events within this period from any of the measurements or from backtrajectory analysis. The first seven days and the last four days of the measurement period no clouds were present at the measurement station, except for a short cloud event on 19 February. From 24 February until 10 March several cloud events took place when orographic clouds formed locally at JFJ or the station was exposed to stratiform clouds. Temperatures during the cloud events ranged between $-6{ }^{\circ} \mathrm{C}$ and $-16^{\circ} \mathrm{C}$. As measurement statistics are limited by the low number of analyzed ice residues, it is not attempted to extend the analysis to the differences between single cloud events. Instead, an average over all the cloud events observed over the time period of the campaign is presented.

All inlets for cloud and aerosol sampling were placed on the top platform with the laboratory underneath, ensuring short inlet lines and minor wall losses on the way to the different instruments. Two different aerosol inlets were used for the measurements. The permanently installed total aerosol inlet, which is part of the Global Atmosphere Watch (GAW) project, is heated to $25^{\circ} \mathrm{C}$ and is designed to sample the total aerosol when no clouds are present (termed ambient or background aerosol) and to sample the entire aerosol population (interstitial aerosol particles, cloud droplet residues and ice residues of hydrometeors up to $40 \mu \mathrm{m}$ ) during cloud conditions (Weingartner et al., 1999). Residence times in the inlet lines from the total inlet to the mass spectrometers were 4$6 \mathrm{~s}$. The other inlet for the selective sampling of small ice particles is the Ice-CVI, which is operated by Leibniz Institute for Tropospheric Research (IfT) Leipzig. This inlet is described in more detail in the following section.

\subsection{Sampling, separation and preparation of ice nuclei with the Ice-CVI}

The sampling principle and the experimentally determined sampling behavior of the Ice-CVI, which consists of four vertically aligned modules, is described in detail by Mertes et al. (2007). The cloud air is aspirated by an omni-directional, exponentially-tapered, upward looking horn. The $90^{\circ}$ sampling with respect to the horizontal wind substantially reduces the undesired collection of ice crystals larger than about $50 \mu \mathrm{m}$, which is the size range above which riming and aerosol impaction scavenging by crystals becomes important and resulting residue particles of such large crystals would thus not only contain the ice nuclei. However, during precipitation periods, the collection of much larger, falling or resuspended, snowflakes and graupel cannot be completely prevented during $90^{\circ}$ sampling, although the inlet is protected by a roof.

In order to remove the precipitating or windblown particles inside the Ice-CVI and to ensure a controlled upper sampling size, a virtual impactor (VI) is connected downstream of the inlet horn. The dimensions are chosen such that particles larger than $20 \mu \mathrm{m}\left(\mathrm{D}_{50 \%}\right.$ cut size diameter) are virtually impacted, whereas smaller particles remain in the sample flow. The upper limit of $20 \mu \mathrm{m}$ is reasonable, because it assures a collection efficiency of nearly 1 for all sampled ice particles and, moreover, the possibility of ice particle break-up in the subsequent Ice-CVI components is minimized by the choice of this upper size limit (Mertes et al., 2007). 
Downstream of the VI a pre-impactor (PI) is installed which separates the small ice particles from supercooled droplets. The latter freeze upon contact with impaction plates colder than $0^{\circ} \mathrm{C}$, while the former bounce off and remain in the sample airflow. A two-stage design was chosen for the PI with upper cut-off diameters of $10 \mu \mathrm{m}$ and $4 \mu \mathrm{m}$ for the supercooled droplets, respectively. Because all sampling was carried out at temperatures below $-5^{\circ} \mathrm{C}$, the impaction plates of the PI were not actively cooled and thus equilibrated with the ambient temperature.

The CVI itself is located downstream of the PI to reject the interstitial particles. The CVI inlet is installed inside a wind tunnel where the incoming air is accelerated to up to $120 \mathrm{~m} \mathrm{~s}^{-1}$, which is needed to reach a $\mathrm{D}_{50 \%}$ cut size of about $5 \mu \mathrm{m}$ (Schwarzenböck et al., 2000). A controlled counterflow is blown out of the inlet tip, which allows only hydrometeors of sufficient inertia to enter the system. The supercooled drops and larger ice crystals have already been removed by the PI and VI, respectively, so only small ice particles $\left(5 \mu \mathrm{m}<\mathrm{D}_{\text {ice }}<20 \mu \mathrm{m}\right)$ are sampled with the lower and upper cut-off diameters determined by the CVI and the VI. Inside the CVI the small ice particles are injected into particlefree and dry carrier air for complete sublimation of the ice, leaving a residue particle in the sample flow for further analysis. Downstream of this section the water vapor representing the sampled ice water content (IWC) and the released residue particles can be analyzed by dedicated instrumentation. The released residue particles are considered to be mainly the original ice nuclei that were responsible for the ice formation in the cloud but it has to be emphasized that the residues were measured after the sublimation of the ice. By use of the inlet horn, the VI, the PI and the CVI, it is ensured that only ice particles in the size range of 5 to $20 \mu \mathrm{m}$ enter the sampling line and are evaporated. These small ice crystals are expected to be freshly formed and are too small to be significantly affected by riming and aerosol scavenging processes. However, secondary ice particles in this size range, if existent, would also be sampled where production processes could be rime splintering, fragmentation during collisions of ice crystals and shattering of some drops during freezing. They mostly will not comprise the original IN but might contain material from the former drop activating $\mathrm{CCN}$, scavenged interstitial particles and trace gases that were taken up and potentially chemically processed by the ice particle. Thus they will leave behind residue particles after evaporation in the CVI as well. However, Mertes et al. (2007) showed that these residues are mainly smaller than about $100 \mathrm{~nm}$ and are clearly size-separated from larger ice residues. As the single particle mass spectrometers only detected particles $>150 \mathrm{~nm}$ (ATOFMS) and $>200 \mathrm{~nm}$ (SPLAT), the ice residues that were chemically analyzed behind the Ice-CVI are assumed to be mainly the original ice nuclei (IN) in the following. Similarly, we consider the droplet residues that are measured behind the Ice-CVI when the pre-impactor is not installed to be cloud condensation nuclei (CCN). Nev- ertheless, the exact determination whether an individual ice residue (IR) (or droplet residue (DR)) is really just the original IN (CCN) or an IN (CCN) plus some additional material or not an IN (CCN) at all is a complex issue that merits further investigation but is beyond the scope of this paper. Furthermore, note that we have no information about the sampling location within the cloud, i.e. cloud base, cloud top, cloud edge or cloud core. Moreover, it is not known which heterogeneous nucleation processes were active (deposition, immersion, contact freezing etc.). The small primary ice particles sampled by the Ice-CVI are those that formed most recently, thus, we may usually do not sample the most efficient IN which form ice particles first. In some sampling situations however, when ice particles just start to form in the cloud, the most efficient ice nuclei are activated and sampled, and in these situations we miss the less efficient ones. Therefore, we can only state that the sampled primary ice particles had to be quite young. Assuming measured ice particle growth rates between 0.4 and $0.9 \mu \mathrm{m} \mathrm{s}^{-1}$ (Mertes et al., 2001) result in ice particles "life times" before sampling between 22 and 50 seconds.

The CVI sampling principle, that is the inertial separation of particles in non-equivalent input and output flows, leads to an enrichment (by a factor 5 to 10 depending on the sampling and detection configuration) of the collected hydrometeors and thus of the residue particles (Ogren et al., 1985). This enrichment provides for improved statistics at the low ambient IR number and mass concentrations encountered during CLACE. Quoted ambient IR concentrations have been corrected for this enrichment factor.

Temperatures in the Ice-CVI are ambient temperatures from the inlet via VI and PI to CVI tip. From the CVI to the sensors, ice particles are injected into dry and particlefree carrier air at lab temperature, i.e. at 25 to $30^{\circ} \mathrm{C}$. Ice-CVI residence times are: $6 \mathrm{~s}$ from inlet via VI and PI to CVI tip: $6 \mathrm{~s}, 0.01 \mathrm{~s}$ from the CVI tip to the evaporation tube, $6 \mathrm{~s}$ inside the evaporation tube and $1-2 \mathrm{~s}$ from the evaporation tube to the sensors.

As the concentration difference between ice particles in the cloud and the interstitial aerosol is very large, it is important to show that the Ice-CVI is very efficient at discriminating the interstitial aerosol. If, for example, only $1 \%$ of the interstitial aerosol particles were able to pass the IceCVI, the spectra from these particles would typically outnumber the IR spectra. To make sure that this is not the case, tests were performed regularly during completely cloud-free periods. When the Ice-CVI was tested under these conditions, the CPC counted about 100-1000 times less particles than during cloud events (CPC concentrations $<0.005 \mathrm{~cm}^{-3}$ vs. $1-10 \mathrm{~cm}^{-3}$ during cloud events). Only the rare particles $>5 \mu \mathrm{m}$ which are not activated will pass the Ice-CVI and are counted during the cloud-free periods. During cloud-events we assume that all particles $>5 \mu \mathrm{m}$ have activated either as $\mathrm{CCN}$ or as IN. Therefore we are confident that the Ice-CVI is very efficient at removing all the ambient aerosol particles 
that are not activated. This test was done in the beginning, several times during and at the end of the campaign.

\subsection{Chemical analysis of single particles}

\subsubsection{SPLAT}

The Single Particle Laser Ablation Time-of-Flight Mass Spectrometer (SPLAT) was developed at the University of Mainz and the Max Planck Institute for Chemistry in Mainz. A full description of the instrument can be found in Kamphus et al. (2008). Here a brief introduction is given.

Particles enter the instrument through an aerodynamic lens assembly which was designed by Schreiner et al. (1999). It consists of seven orifices with decreasing diameters from $1300 \mu \mathrm{m}$ to $650 \mu \mathrm{m}$. The final accelerating orifice has an inner diameter of $200 \mu \mathrm{m}$. The lens is optimized to focus particles with a vacuum aerodynamic diameter $\left(d_{v a}\right)$ of $300 \mathrm{~nm}$ to $3.0 \mu \mathrm{m}$ into a narrow particle beam. During the CLACE 6 campaign the inlet pressure of the aerodynamic lens was held constant at 90 mbar. At this working pressure particles with a $d_{v a}$ between $300 \mathrm{~nm}$ and $400 \mathrm{~nm}$ are detected with highest overall efficiency.

After passing the aerodynamic lens, the velocity of the particles, and thus their vacuum aerodynamic diameter, is measured by light scattering at two locations separated by $28 \mathrm{~mm}$. The light of a $532 \mathrm{~nm} \mathrm{cw}$ Nd:YAG laser is coupled into a glass fiber equipped with a 50/50 splitter. At the exit of the two fibers the laser beam is focused with a gradient index lens. The scattered light from particles passing through the laser beam is collected in the direction of the laser beam propagation with two lenses, spatially filtered with a $200 \mu \mathrm{m}$ pinhole and detected with a photomultiplier. From the flight time between the two light scattering signals the particle velocity, and hence the time required to trigger the ablation laser, are calculated. The ablation laser is an ArF excimer laser operating at $193 \mathrm{~nm}$ with pulse duration of $8 \mathrm{~ns}$. The laser beam is focused with a $270 \mathrm{~mm}$ focal length lens onto the particle beam resulting in power densities of $6.6 \times 10^{9} \mathrm{~W} \mathrm{~cm}^{-2}$. When the laser pulse hits the particle its components are evaporated and ionized. The resulting ions are detected in a bipolar time-of-flight mass spectrometer equipped with reflectrons. Thus, for every particle detected by both sizing lasers and hit by the ablation laser, information about the size and its chemical composition is obtained. Not every particle, which is sized, is hit by the ablation laser and generates a measurable mass spectrum. Therefore, for some particles only the size information is available.

The time-of-flight spectra are converted into mass spectra and are integrated for integer masses up to $m / z 220$ for positive and negative ions. No signals were found beyond this value. The resulting vector contains all information about the positive and negative ion spectrum for each particle and is stored consecutively in a matrix. Further data analysis is performed with this matrix.
For classification of mass spectra of single particles different classification algorithms like k-means (e.g. Zelenyuk et al., 2006), fuzzy c-means (e.g. Hinz et al., 1999) and ART2a neural networks (e.g. Zhao et al., 2005; Zhou et al., 2006) were used and discussed in the literature. A comparison of different clustering algorithm is presented by Hinz and Spengler (2007) and Rebotier and Prather (2007). For analysis of the SPLAT single particle data the open source data mining program Rapid Miner Version 4.1 (Mierswa et al., 2006) was used. Classifications were performed using a $k$ means algorithm and varying the number of class centers, which is the mean value of all particles belonging to a certain class, from two to ten. The classification algorithm is optimizing the location of the class center in the way that the distance between particles which belong to a certain class center is minimized in comparison to the distance between the class centers. Compared to the fuzzy $c$-means classification where particles can be member of more than one class (soft classification), the $k$-means algorithm assigns a paticle to exactly one class (hard classification). On the basis of the Davies Bouldin validation index (Maulik and Bandyopadhyay, 2002), and by evaluating the MS-spectra for the cluster center depending on the number of classes, the appropriate number of classes was found for classifying the ice residues, the background aerosol and the droplet residues measured with the SPLAT instrument.

In addition to the k-means algorithm analysis, the peak height for each of the most frequently detected ions is recorded for every particle. This allows to determine how frequent some individual species (e.g. lead) are detected independent of affiliation to a class.

Size calibration of the SPLAT instrument was performed at the beginning of the CLACE campaign with PSL spheres. As the position of the detection lasers was not changed during the campaign further calibrations were not necessary. Mass calibration was carried out with external calibration at the beginning of the campaign and was refined during the campaign by internal calibration.

\subsubsection{ATOFMS}

The TSI Model 3800 Aerosol Time of Flight Mass Spectrometer (ATOFMS) is a commercially available single particle mass spectrometer. It has been described in detail previously by Gard et al. (1997). A brief description follows.

The ATOFMS functions in a manner similar to most single particle laser ablation instruments. There are, however, instrument-to-instrument differences to the SPLAT that bear noting. Aerosol enters the instrument through an aerodynamic lens optimized for vacuum aerodynamic diameters $\left(d_{v a}\right)$ between $100 \mathrm{~nm}$ and $600 \mathrm{~nm}$ (Liu et al., 1995a, b). Particles and gas-phase molecules smaller, and particles larger than these limits are not focused as efficiently and are mostly removed via differential pumping stages. Therefore, it was not possible to detect particles 
larger than $2000 \mathrm{~nm} d_{v a}$ during CLACE 6. Particles within this range are imparted with a $d_{v a}$-dependant velocity. After exiting the lens, particles are detected and optically sized using the transit time between two continuous $532 \mathrm{~nm}$ frequency-doubled neodymium-doped yttrium aluminum garnet (Nd:YAG) lasers. Insufficient scattered light leads to reduced detection efficiency below $\sim 300 \mathrm{~nm} d_{v a}$, although this limit is ultimately dependent on the specific light scattering property of the particle. No particles smaller than $150 \mathrm{~nm} d_{v a}$ were detected during CLACE 6.

The measured velocity is calculated and used to trigger a $266 \mathrm{~nm}$ frequency-quadrupled Nd:YAG laser at a time appropriate to strike the particle. The purpose of this laser is the same as that of the excimer laser in the SPLAT instrument (i.e., to ablate and ionize the particle). The benefit of the $266 \mathrm{~nm}$ YAG is that it is a robust, solid state laser that does not require complex optics or daily maintenance, for example the change of the gas charge, that an excimer laser does. The downside is that the longer wavelength of this laser limits the components which can be detected. For example, pure sulfates and organics do not absorb sufficient radiation at this wavelength to produce ions and, ultimately, a mass spectrum (Thomson and Murphy, 1993; Thomson et al., 1997).

After creation, ions are accelerated in opposite directions down dual linear reflectrons, allowing both positive and negative mass spectra to be recorded for each individual particle. An ideal 'event' thus results in a record of particle $d_{v a}$ as well as a positive and negative ion mass spectrum. Negative ions are sometimes not detected (i.e., they are harder to create than positive ions, see below). Particles which pass through only one of the sizing lasers do not generate a recorded signal. Particles which pass through both sizing lasers but are not struck by the ablation and ionization laser, or which do not produce ions, produce a $d_{v a}$ record.

The ATOFMS is operated with software provided by TSI. Cluster analysis was performed using the open source software Enchilada (Gross et al., 2006). This requires a periodic calibration using input of known size PSL spheres to allow for the determination of particle size. The procedure lasts approximately one hour and was performed every two days. PSL spheres of 260, 300, 500, 670, 1000, and $2000 \mathrm{~nm}$ were used. Calibration of the mass spectrum requires input of aerosol with known components to correlate flight time in the mass spectrometer to a known mass peak. This process requires approximately 30 minutes and was performed daily during CLACE 6.

\subsection{Optical particle counter measurements}

An optical particle counter (OPC) (Grimm, 1.108) was operated at the same inlet as the SPLAT instrument. The OPC uses 15 channels for measuring particle size distributions larger than $300 \mathrm{~nm}$ with a $6 \mathrm{~s}$ time resolution. Particles larger than $20 \mu \mathrm{m}$ are detected in the last channel. As the OPC measures in the same size range (particles $>300 \mathrm{~nm}$ in diame-

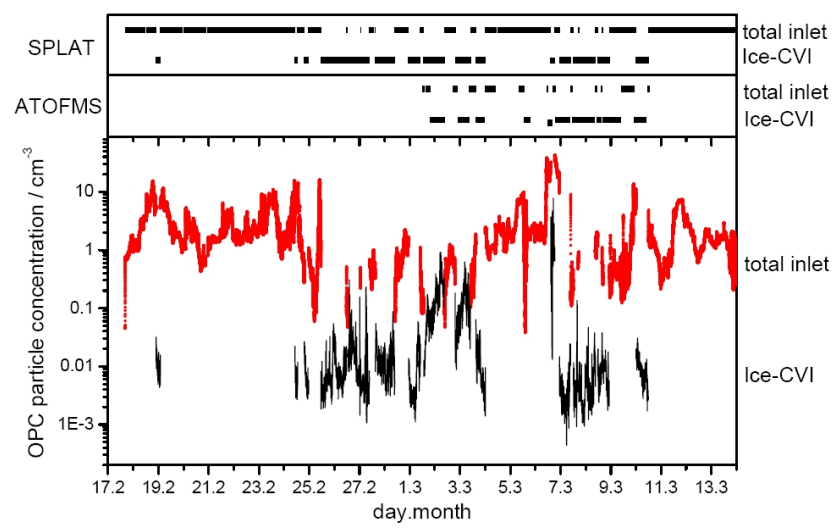

Fig. 1. SPLAT (upper panel) and ATOFMS (middle panel) instruments connected to the total inlet and Ice-CVI. For the measurements of 6 March the CVI was operated in droplet mode with the pre-impactor removed. Lower panel shows particle concentrations measured with an OPC. Mean particle concentrations with diameters $>300 \mathrm{~nm}$ were 2.6 particles $\mathrm{cm}^{-3}$ at the total inlet (red trace) and 0.03 particles $\mathrm{cm}^{-3}$ at the Ice-CVI (black trace, corrected for Ice-CVI enhancement factor).

ter) as the two single particle mass spectrometers, it delivers an important comparative measurement of particles size and concentration. It is not intended to discuss the size distributions measured by the OPC in detail, instead for the present study the OPC is mostly used as an indicator of the total number of particles $>300 \mathrm{~nm}$ in diameter that are present in the sampling line after the inlet. For a more detailed discussion of size distributions of ice residues etc., see Mertes et al. (2007).

\section{Results}

During the CLACE 6 field experiment the SPLAT instrument was operated from 17 February to 13 March with only short interruptions for realignment of the particle beam and lasers.

Similarly, during periods of mixed-phase clouds the ATOFMS was connected to the Ice-CVI inlet as well. For some periods out of cloud the ATOFMS remained connected to this inlet to verify zero particle counts. At other times the instrument was switched to the total aerosol inlet.

The ATOFMS was operated from 1 through 10 March 2007 for these studies. During the early portion of the CLACE campaign the ATOFMS did not sample due to a failure and subsequent replacement of the desorption and ionization laser. After 10 March, and during the open intervals in the schedule displayed in Fig. 1, the ATOFMS was also utilized to investigate hygroscopic growth of particles (Herich et al., 2008).

DR were sampled by both mass spectrometers during the 6 March period when the pre-impactor was removed from 
the Ice-CVI. During overnight hours both instruments were often operated at a single inlet unattended.

\subsection{Concentration and size distribution of background aerosol particles, ice residues and cloud droplet residues}

During the presence of mixed-phase clouds the two single particle mass spectrometers operated at the Ice-CVI, otherwise sampling from the total inlet. The upper panel of Fig. 1 shows at which inlet the SPLAT instrument and the OPC were operated during CLACE 6 . The middle panel shows the time periods when the ATOFMS measured at the total or the Ice-CVI inlet. Furthermore, the particle concentration measured with the OPC is plotted in the lowest panel. The arithmetic mean concentration of particles with diameters larger than $300 \mathrm{~nm}$ over all measurement periods of CLACE 6 was 2.6 particles $\mathrm{cm}^{-3}$ at the total inlet and 0.03 particles $\mathrm{cm}^{-3}$ at the Ice-CVI, respectively, after correction for the ICE-CVI enhancement factor.

Despite the low particle concentration after the Ice-CVI, mass spectra of 355 ice residues, 162 droplet residues (measurements of 6 March with the droplet pre-impactor removed at the Ice-CVI) and 9764 background aerosol particles were analyzed by the SPLAT instrument and 152 ice residues, 1094 droplet residues, and 3212 background particles were analyzed by the ATOFMS, respectively. Figure 2 shows the overall size statistics of the background aerosol particles, ice residues, and droplet residues analyzed by the SPLAT and the ATOFMS instruments. This figure indicates the typical sizes of the particles that were chemically analyzed by the two mass spectrometers. The size distributions from the two instruments do not represent the true size distributions of the respective particles in the sampling line because the detection efficiency of single particle instruments varies strongly with particle size as discussed in detail above and by Kamphus et al. (2008).

It is not possible to quantify exactly the size-dependent detection efficiencies for the present measurements. The particle shape and density influences the detection efficiency significantly and therefore the findings from laboratory studies with spherical PSL particles (Kamphus et al., 2008) cannot be transferred directly to the background aerosol particles, ice and droplet residues measured in the field. As mentioned above, for the SPLAT instrument the detection efficiency at $300-400 \mathrm{~nm}$ particle size is over-represented.

Besides the different particle-size dependent detection efficiencies of the two mass spectrometers also note that the time periods of measurement throughout CLACE 6 were only partly overlapping as indicated in Fig. 1, due to instrumental constraints, use of the ATOFMS for hygroscopicity studies, etc. Therefore, the size measurements from the two instruments should not be compared directly as the aerosol sampled at different times had different size characteristics. Only for the measurement of the droplet residue on 6 March and for the background measurements before and after the DR event, both spectrometers were measuring and statistically sufficient particles were sampled, so for this measurement period a direct comparison is performed.

Furthermore, a comparison of the size information from the two single particle mass spectrometers to the sizeresolved measurements from the OPC is limited. The densities and the refractive indices of the particles have to be known to be able to compare the vacuum aerodynamic diameter from the single particle instruments with particle diameters inferred from the OPC measurements directly. Furthermore, the OPC gives only very crude size information for particles $<1 \mu \mathrm{m}$ compared to the size resolution of the mass spectrometers. Nevertheless, from a comparison with the OPC data it can be seen that there is a clear drop in the efficiency when particles were analyzed with sizes below $300 \mathrm{~nm}$ for both, the SPLAT and the ATOFMS instrument. Furthermore, there are relatively few particles observed above $1 \mu \mathrm{m} d_{v a}$ by the mass spectrometers during CLACE 6. This is due to both, the low concentrations and less efficient analysis at these sizes. Note also that a small fraction of particles extend beyond the range of the histograms.

The size distributions shown in Fig. 2 contain variations. At the total inlet most of the detected particles had diameters of $350-700 \mathrm{~nm}$. The size statistics for the background aerosol over the whole measurement period show a bimodal size distribution. This is largely attributed to the integral statistics for the long time period as the aerosol size distribution varied over the course of the campaign. Specifically, there was a larger average aerosol particle size during cloud-influenced periods whereas in periods without clouds the smaller mode at $300-400 \mathrm{~nm}$ dominated.

The ice residue mode diameter was larger than that of the total aerosol, with most particles analyzed with $350-450 \mathrm{~nm}$ size for the SPLAT and 500-700 $\mathrm{nm}$ for the ATOFMS. Larger yet was the mode diameter of the DR particles, peaking at $\sim 600 \mathrm{~nm}$. The addition of DR mass due to sulfate production by aqueous phase cloud processing may have added considerably to the large size of the droplet residuals. For the SPLAT and ATOFMS data, there was a noticeable, almost step-like increase in particle concentration just below $600 \mathrm{~nm} d_{v a}$.

\subsection{SPLAT results: chemical characterization of background aerosol particles, ice and droplet residues}

\subsubsection{Background aerosol particles}

Classification for the background aerosol particles (BG) is performed for all data collected between 17 February and 13 March, whenever the SPLAT was not connected to the IceCVI. During that time, 9764 particles were chemically analyzed with the SPLAT instrument which yielded a positive 


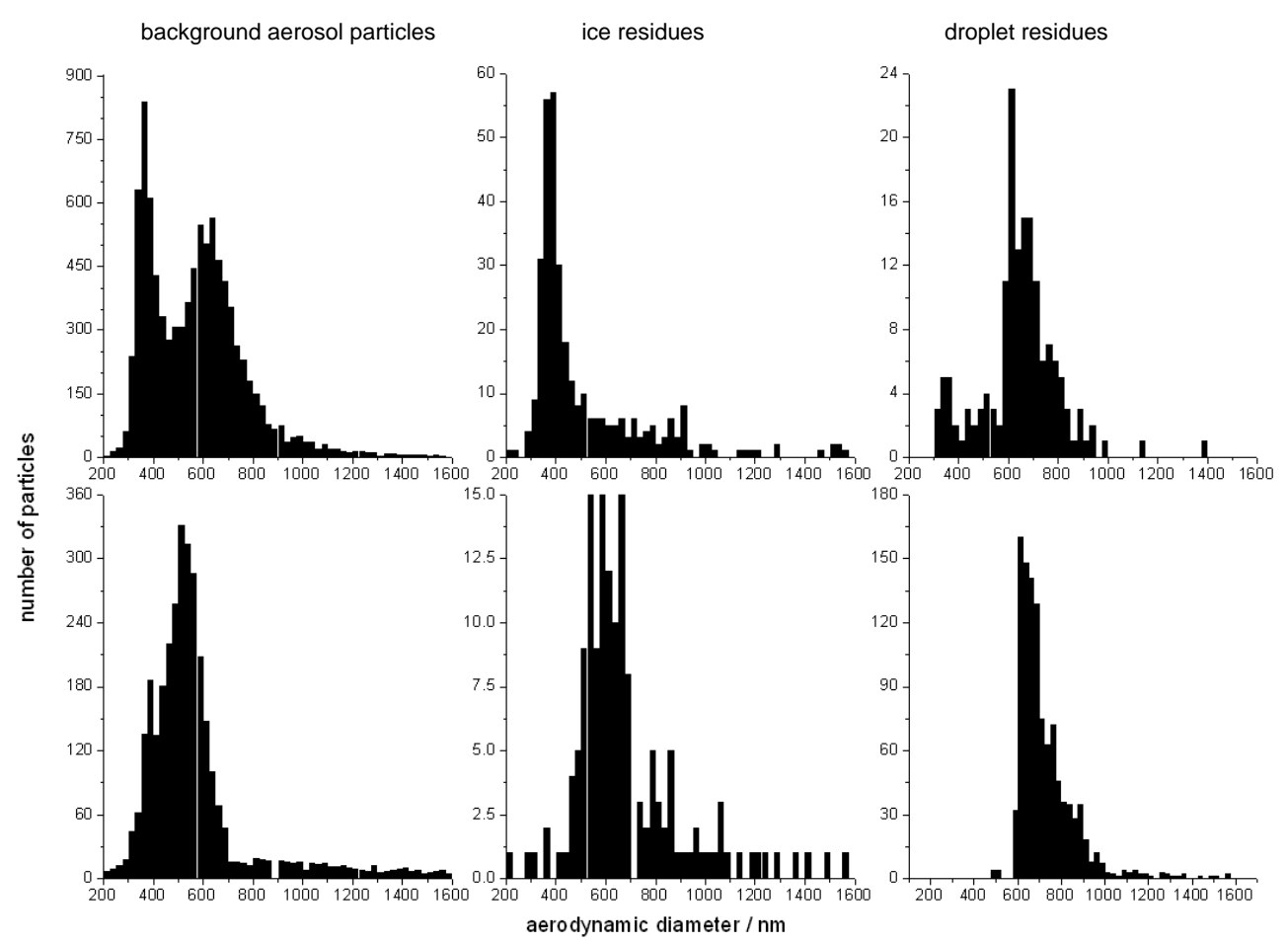

Fig. 2. Overall size statistics of the background aerosol particles (left), cloud ice residues (middle) and cloud droplet residues (right) detected with the SPLAT instrument (upper row) and the ATOFMS (lower row) during CLACE 6 for the different particle types. Note that these do not represent the actual particle size distributions but represent the sizes of particles that are chemically analyzed instead (see text).

and a negative ion mass spectrum. This may introduce some bias into the classification as only those particles are analyzed where some negative ion spectrum could be generated. In addition to the broad average over all BG data of the campaign, as a case study for one specific sitation, for the BG aerosol measured before and after the DR event on 6 March a classification is generated. This allows a comparison between the DR and BG data when comparing the data for the same meteorological situation.

With the $k$-means clustering approach six different classes for the background aerosol were found, which are presented in Fig. 3. Class 1 and 2 show the strongest signals for mineral dust, especially peaks from $\mathrm{Si}, \mathrm{SiO}, \mathrm{Al}, \mathrm{Ca}$ and $\mathrm{CaO} / \mathrm{Fe}$ are detected in both classes. They both sum up to $\sim 17 \%$ of the background aerosol particles. The biggest difference between these two classes is their sulfate signal. In class 1 there is hardly any sulfate, whereas in class 2 sulfate represents a strong anion signal. This indicates most likely that particles of class 1 are relatively fresh mineral dust particles that have not been coated by sulfate and other liquid secondary aerosol components during atmospheric processing, while particles of class 2 seem to be more aged and at least partly coated.

Whenever strong signals for mineral dust were found, signals from $m / z 1$ to $m / z 6$ in the negative ion spectrum are present which cannot be assigned to reasonable ions. We tested the influence of these signals by conducting another classification with the intensity for the negative ion mass channels 1 to 6 set to zero. The resulting class centers were very similar to those presented in Fig. 3 (the percentages for the different classes only changed between $1 \%$ and $2 \%$ ). This demonstrates that the negative ion mass signals at $m / z 1$ to $\mathrm{m} / z 6$ do not influence the classification results.

Almost 50\% of the background particles belong to class 3, which is strongly dominated by signals from sulfate $\left(\mathrm{HSO}_{4}^{-}\right)$, nitric oxide $\left(\mathrm{NO}^{+}\right)$, carbon/organics, potassium and nitrate. This class characterizes mostly the typical soluble background aerosol of inorganic and organic secondary aerosol, which is liquid at the encountered temperatures and relative humidity conditions. In class 4 sulfate is also the strongest signal in the anionic spectrum but different to the former class the relation between carbon/organic signals and $\mathrm{NO}^{+}$ signals changes substantially. Nitrates are hardly found, but signals characteristic for mineral dust appear. Along with the signal from $\mathrm{HSO}_{4}^{-}$at an ion mass to charge ration of $97 \mathrm{amu}$ a signal at 55 or 56 amu is frequently detected (see Fig. 3). It is probably caused by a secondary electron process within the time-of-flight region and does not represent a regular signal.

Finally, in classes 5 and 6 which play only a minor role for the background aerosol particles, potassium is the strongest signal. Class 5 exhibits the largest variety of negative ions: $\mathrm{HSO}_{4}^{-}, \mathrm{Cl}^{-}, \mathrm{CNO}^{-}, \mathrm{NO}_{2}^{-}$and $\mathrm{C}_{2} \mathrm{H}_{\mathrm{x}}^{-}$and $\mathrm{CH}_{\mathrm{x}}^{-}$. Chloride 


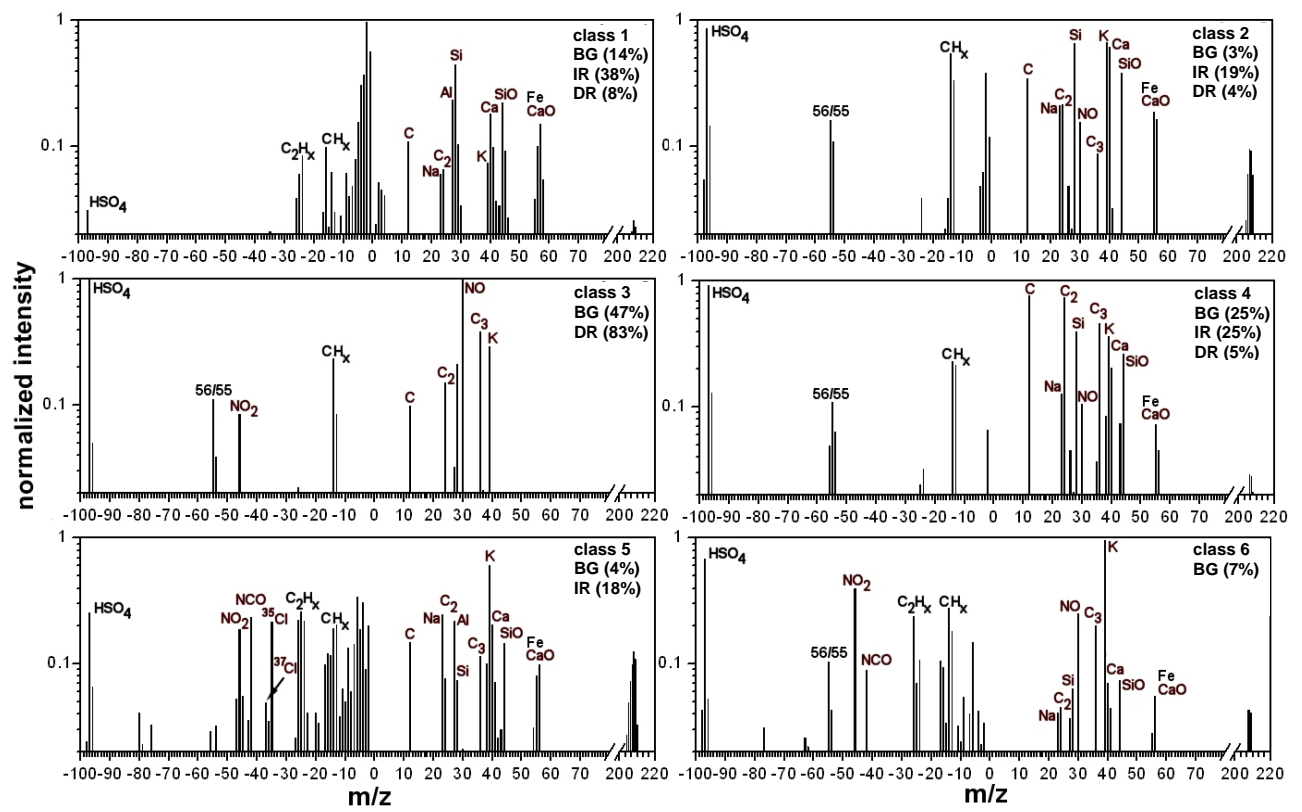

Fig. 3. Cluster centers from the classification of background aerosol particles (BG), ice residues (IR) and droplet residues (DR). For each class only one example from the background aerosol particles or the ice residue SPLAT measurements is given.

is not found in any other class. In the positive ion spectrum sodium, mineral dust and signals for carbon/organics were found besides potassium. In class $6 \mathrm{NO}^{+}$signals are more important while signals for sodium, carbon/organics and mineral dust are depleted.

All classes, except class 1, show a fairly high degree of internal mixing for the background aerosol, which is indicative for processed, aged aerosol, as expected at a rather remote site. Note that class 1 is also the class with the lowest sulfate signals. There is hardly any class described by mass signals which cannot be found in one of the other classes at all. The relation of the intensity of different mass signals is the most important criterion for defining the different particle classes.

Table 1 lists how frequently individual chemical compounds are found in the BG particles. The table gives the fraction of particles for which the compound is found with a count rate of more than $10 \%$ (or more than $1 \%$ ) of the maximum peak of the spectrum.

\subsubsection{Cloud ice residues}

When mixed phase clouds were present and the Ice-CVI was operated, the SPLAT instrument and the OPC were connected to the Ice-CVI. During that time 355 individual ice residues (IR) were chemically analyzed with a positive and negative ion mass spectrum. The ice residues were sampled during 12 individual cloud phases between 24 February and 10 March. The individual cloud phases lasted from $3 \mathrm{~h}$ to $>48 \mathrm{~h}$. A large fraction of the spectra (167 IN) were acquired between 1 March, 13:30, and 2 March, 09:00, when the OPC measured relatively high particle concentrations of up to 0.55 particles $\mathrm{cm}^{-3}$. Backward trajectories calculated with the LME (Local Model Europe) by the DWD (Deutscher Wetterdienst) showed strong westerly flow conditions for that time period. Wind speeds of up to $15 \mathrm{~m} / \mathrm{s}$ were encountered. This raises the risk of windblown snow crystals and secondary ice passing the inlet. It is shown by Mertes et al. (2007) that the residues of such secondary particles are generally smaller than $200 \mathrm{~nm}$ and would therefore not be detected by the single particle mass spectrometers. Analyzing the particles from this period separately from all other ice residue samples shows that the results are very similar (cf. Table 1) and therefore a bias seems unlikely.

Almost $60 \%$ of the IR spectra are dominated by mineral dust (class 1 and 2). Class 4 (sulfate with strong carbon/organic signals) is found for the ice residues in similar abundance as for the background aerosol (25\%). Note, that besides the high signals from sulfate and (hydro)carbons that are mainly responsible for the k-means classification, particles in class 4 have also pronounced peaks from $\mathrm{Si}, \mathrm{SiO}$, $\mathrm{K}, \mathrm{Ca}, \mathrm{Na}$ and other compounds indicating the presence of mineral dust inclusions also in these particles. Class 5, dominated by potassium signals and most likely representative of biomass burning aerosol, comprises also a fairly large fraction of the ice residues. Note that this is consistent with recent remote sensing (Lin et al., 2006; Sassen and Khvorostyanov, 2008) and laboratory studies (Petters et al., 2009) which suggest that smoke particles can impact ice nucleation in the atmosphere. Many of the components that comprise class 5 , including potassium, nitrite, chloride and sodium, were shown to be correlated with the production of 
Table 1. Frequency of occurrence of a signal strength of $>10 \%$ ( $>1 \%$, respectively) for the listed ion compared to the largest peak of the spectrum for the SPLAT data; example: in $11 \%$ of all background particle spectra the $\mathrm{CH}^{-}$peak was at least as high as $10 \%$ of the highest peak of the spectrum (normalized intensity $>0.1$ ).

\begin{tabular}{|c|c|c|c|c|c|c|c|c|c|c|c|c|}
\hline \multirow[b]{2}{*}{ Neg. ions } & \multicolumn{2}{|c|}{ BG all } & \multicolumn{2}{|c|}{ IR all } & \multicolumn{2}{|c|}{ IR $1+2$ March } & \multicolumn{2}{|c|}{ IR all except $1+2$ March } & \multicolumn{2}{|c|}{ DR 6 March } & \multicolumn{2}{|c|}{ BG 6 March } \\
\hline & $f_{>0,1}$ & $f_{>0,01}$ & $f_{>0,1}$ & $f_{>0,01}$ & $f_{>0,1}$ & $f_{>0,01}$ & $f_{>0,1}$ & $f_{>0,01}$ & $f_{>0,1}$ & $f_{>0,01}$ & $f_{>0,1}$ & $f_{>0,01}$ \\
\hline $\mathrm{CH}$ & 0.11 & 0.32 & 0.32 & 0.49 & 0.33 & 0.50 & 0.33 & 0.53 & 0.41 & 0.54 & 0.03 & 0.20 \\
\hline $\mathrm{CH}_{2}$ & 0.14 & 0.29 & 0.41 & 0.60 & 0.44 & 0.64 & 0.40 & 0.59 & 0.72 & 0.77 & 0.14 & 0.28 \\
\hline $\mathrm{C}_{2} \mathrm{H}$ & 0.07 & 0.23 & 0.17 & 0.32 & 0.19 & 0.34 & 0.15 & 0.31 & 0.01 & 0.06 & 0.16 & 0.53 \\
\hline $\mathrm{C}_{2} \mathrm{H}_{2}$ & 0.11 & 0.31 & 0.15 & 0.30 & 0.18 & 0.34 & 0.10 & 0.27 & 0.04 & 0.11 & 0.27 & 0.70 \\
\hline $\mathrm{NO}_{2}$ & 0.16 & 0.32 & 0.09 & 0.16 & 0.08 & 0.14 & 0.11 & 0.20 & 0.08 & 0.14 & 0.49 & 0.83 \\
\hline $\begin{array}{l}\mathrm{HSO}_{4} \\
\text { Pos ions }\end{array}$ & 0.83 & 0.87 & 0.51 & 0.54 & 0.52 & 0.54 & 0.54 & 0.57 & 0.94 & 0.96 & 0.79 & 0.86 \\
\hline $\mathrm{C}_{1}$ & 0.55 & 0.79 & 0.52 & 0.69 & 0.43 & 0.62 & 0.72 & 0.88 & 0.22 & 0.74 & 0.44 & 0.87 \\
\hline $\mathrm{Na}$ & 0.10 & 0.27 & 0.37 & 0.60 & 0.41 & 0.63 & 0.32 & 0.59 & 0.06 & 0.14 & 0.06 & 0.16 \\
\hline $\mathrm{C}_{2}$ & 0.57 & 0.86 & 0.44 & 0.64 & 0.42 & 0.62 & 0.52 & 0.73 & 0.23 & 0.60 & 0.45 & 0.88 \\
\hline $\mathrm{Al}$ & 0.09 & 0.55 & 0.22 & 0.42 & 0.25 & 0.39 & 0.18 & 0.52 & 0.07 & 0.15 & 0.04 & 0.39 \\
\hline $\mathrm{Si}$ & 0.66 & 0.91 & 0.67 & 0.78 & 0.72 & 0.81 & 0.63 & 0.79 & 0.47 & 0.96 & 0.66 & 0.97 \\
\hline NO & 0.74 & 0.91 & 0.25 & 0.60 & 0.24 & 0.57 & 0.30 & 0.71 & 0.93 & 0.98 & 0.94 & 0.99 \\
\hline $\mathrm{C}_{3}$ & 0.47 & 0.76 & 0.30 & 0.45 & 0.31 & 0.41 & 0.31 & 0.56 & 0.13 & 0.36 & 0.65 & 0.84 \\
\hline $\mathrm{K}$ & 0.56 & 0.83 & 0.60 & 0.73 & 0.63 & 0.76 & 0.57 & 0.74 & 0.31 & 0.62 & 0.67 & 0.89 \\
\hline $\mathrm{Ca}$ & 0.11 & 0.21 & 0.52 & 0.73 & 0.56 & 0.80 & 0.49 & 0.67 & 0.10 & 0.15 & 0.07 & 0.17 \\
\hline $\mathrm{SiO}$ & 0.13 & 0.31 & 0.52 & 0.70 & 0.59 & 0.76 & 0.44 & 0.63 & 0.09 & 0.11 & 0.08 & 0.20 \\
\hline $\mathrm{Fe}$ & 0.09 & 0.21 & 0.25 & 0.51 & 0.26 & 0.53 & 0.25 & 0.52 & 0.04 & 0.09 & 0.09 & 0.18 \\
\hline $\mathrm{Pb}$ & 0.07 & 0.09 & 0.21 & 0.40 & 0.22 & 0.42 & 0.21 & 0.39 & 0.02 & 0.04 & 0.00 & 0.00 \\
\hline
\end{tabular}

ice nuclei from fires in the Petters et al. study. Class 3 (characterized by strong sulfate and $\mathrm{NO}^{+}$signals), which is dominating the background classification with almost 50\% and which is typical for soluble aerosol particles, was not found for the ice residue classification at all. Note that in this class mineral compounds like $\mathrm{Si}, \mathrm{SiO}, \mathrm{Ca}$ and $\mathrm{Na}$ are virtually absent (Fig. 3).

As can be seen in Fig. 3 some of the classes show signals at a mass to charge ratio of 206-208 which can be identified as the characteristic isotopic pattern of lead $\left({ }^{206} \mathrm{~Pb}^{+}-{ }^{208} \mathrm{~Pb}^{+}\right)$. Signals from lead were detected with SPLAT in $9 \%$ of the background aerosol particles and in $40 \%$ in the IR. Although lead was frequently detected in the BG and IR particles it was not a compound that was specific to certain particle classes when applying the $k$-means classification. It seems that lead indeed is a compound that enhances ice nucleation considerably. The lead most likely stems from combustion of leaded fuel that is still allowed to be used today for aviation fuel of helicopters and small aircraft. After combustion, the lead attaches to various particle types. A detailed discussion of the enhanced frequency of lead occurence in ice residues, its effects for ice nucleation and the consequences for cloud formation and climate, including a discussion of the ice residual data from the CLACE 6 campaign is given by Cziczo et al., 2009, therefore we will not extend the discussion of this issue here. Earlier studies already suggested that lead, especially in the form of lead iodide, plays a role for ice nucleation (e.g.,
Schaefer, 1945 and 1966; Borys and Duce, 1979; Detwiler and Vonnegut, 1981).

The lead found in various classes after the $k$-means classification, albeit with relatively small signal strength, demonstrates a general issue of the classification for the ice residuals. The ability of a particle to act as an ice nucleus may depends on small amounts of certain substances that do not make up the main components of the particle which determine the classification. Therefore, Table 1 lists the frequency of occurrence for various compounds detected by SPLAT with signal strengths larger than $10 \%$ (and larger than $1 \%$, respectively) of the highest signal found in the particle spectra, independent of the classification. This shows that especially mineral and metal compounds like $\mathrm{Ca}, \mathrm{Na}, \mathrm{SiO}, \mathrm{Fe}$ and $\mathrm{Pb}$ are found with considerably higher frequency in ice residues than in the background aerosol.

\subsubsection{Cloud droplet residues}

On 6 March 2007, the droplet pre-impactor of the CVI was removed for one day of measurement. In this configuration the CVI samples ice particles as well as supercooled cloud droplets. The droplets outnumber the ice particles by a factor of $\sim 100$. From 14:35 to $18: 30$ the SPLAT instrument analyzed 162 individual particles with a positive and a negative ion mass spectrum. The OPC measured total particle concentrations for particle sizes $>300 \mathrm{~nm}$ between 0.05 particles $\mathrm{cm}^{-3}$ and 3.1 particles $\mathrm{cm}^{-3}$. Five-day 
backward trajectories calculated with the LME model by the DWD showed that air masses were coming from the Iberian Peninsula and the western Mediterranean Sea during this period.

For the DR the composition changes completely compared to the IR. Predominantly sulfate and nitrate $\left(\mathrm{NO}^{+}\right)$are found. Class 3 makes up $83 \%$ of the particles, $\mathrm{HSO}_{4}^{-}$and $\mathrm{NO}^{+}$are detected with signals larger than 0.1 of the normalized intensity in $94 \%$ and $93 \%$ of the particles (Table 1). The other classes 1, 2 and 4 contribute to the droplet residues only to a very small extent. Class 5 , dominated by potassium accompanied by a variety of anions, and class 6 , potassium with nitrates, were not found for the DR classification on this day. Note that potassium is still present in $\sim 31 \%$ of the DR particles with signal strength $>0.1$ of the maximum signal, but is substantially less frequent than in the BG particles of 6 March (67\%; Table 1).

\subsubsection{Comparison of particle class abundance for ice and droplet residues and background aerosol particles}

Due to the low particle concentrations, for the ice residues only mean particle populations are compared, averaged over long time periods with air masses coming from different regions. Therefore, only general statements on the chemical composition of the IR are made and it is not attempted to discuss the temporal evolution of the IR composition or differences in IR composition as a function of cloud type, temperature during sampling, etc. Nevertheless, it can be seen from Table 1 that the IR analyzed, e.g., just during 1 and 2 March do not show a substantially different composition from the IR analyzed over the rest of the campaign.

It is not justified to compare IR composition from one period with $\mathrm{BG}$ paricles from another period, when the origin of the air masses and the particle sources were different. Therefore, a direct comparison of the pie charts of Fig. 4 for the different particle types is limited. If comparisons are made these should be regarded as qualitative. For a more substantial direct comparison, only the time period of 6 March is analyzed in detail, when statistically sufficient numbers of BG and DR particles were sampled in comparable air mass conditions and when both mass spectrometers operated simultaneously.

The abundances of the different particle classes are given in Fig. 4 as percentages for the background aerosol particles, ice and droplet residues. For the IR it can be seen that class 1 and class 2 , which are dominated by mineralic compounds, account for $57 \%$ of the IR particles. The mineral class with minimal sulfate (class 1) represents $38 \%$ of the total IR. This class can also be found for the BG and DR but in these cases only $14 \%$, and $8 \%$ respectively, of the analyzed particles are classified into these categories. The mineral class with sulfate (class 2) constitutes $19 \%$ of the IR particles but only $4 \%$ of the DR and $3 \%$ of the BG. In summary, this demonstrates

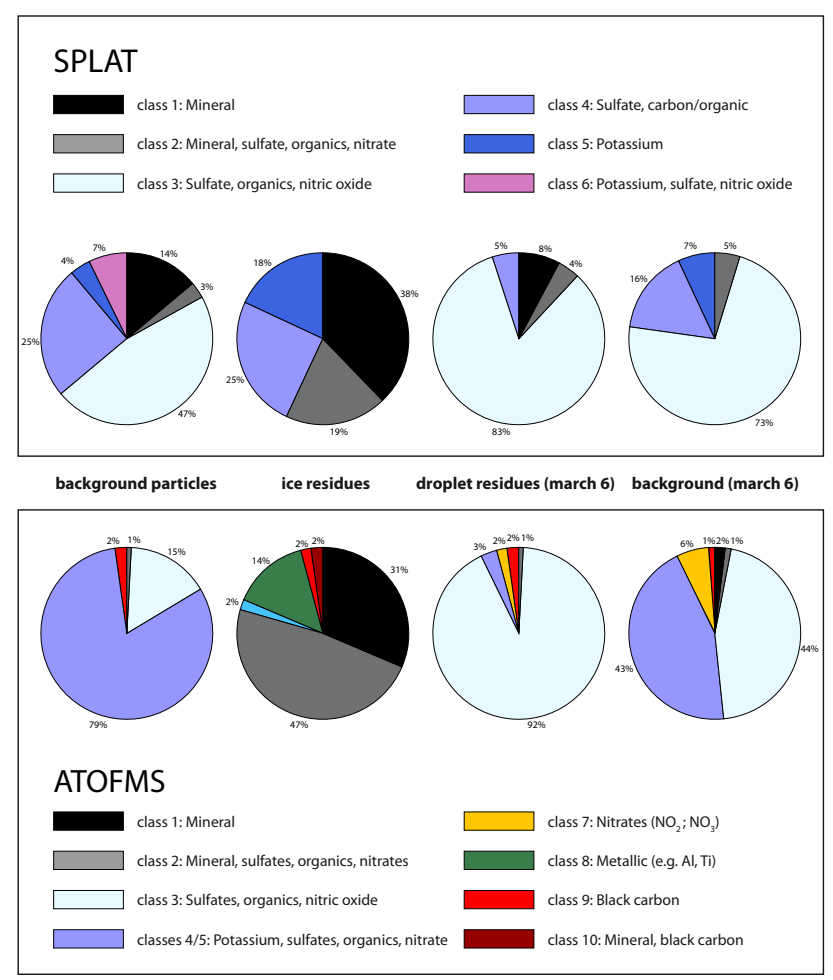

Fig. 4. Frequency of occurrence of particle classes for SPLAT (upper row) background particles (9764), ice residues (355), droplet residues (6 March, 162), background particles (6 March). ATOFMS (lower row) background particles (3212), ice residues (152), droplet residues (6 March, 1094), background particles (6 March).

the important role of mineral components for the ability of a particle to act as an efficient ice nucleus in the atmosphere.

Another chemical component which exhibits strong variations between IR, BG and DR is sulfate. For the IR classification strong sulfate signals can be found in class $2(19 \%)$ and class $4(25 \%)$. Together they account for $44 \%$ of the IR. The classification for the background aerosol resulted in three classes with strong sulfate signals: class 3 (47\%), class $4(25 \%)$ and class $6(7 \%)$. All three classes sum up to $79 \%$ which shows that sulfate is depleted, on a particle number basis, in the ice residues. Class 3 , characterized by a strong signal for $\mathrm{HSO}_{4}^{-}$and $\mathrm{NO}^{+}$, is not present in the IR classification at all but is very common in the DR classification (83\%). In addition, class 2 and class 4 also contain strong sulfate signals. In total, $92 \%$ of the DR contain significant sulfate. Comparing this high level of sulfate in class 2-4 with the classes 2-4 for the BG particles of 6 March shows that sulfate particles were generally very high on that day. Similarly, the $\mathrm{HSO}_{4}^{-}$peak in the mass spectra had a level of $>10 \%$ of the highest peak in $94 \%$ of the DR spectra, and in $79 \%$ of the BG spectra of 6 March (Table 1). Cloud processing of sulfur might have enhanced the sulfate in the DR particles additionally. 
Class 5 is found in the IR and BG classification (Fig. 3), which shows mainly potassium combined with some mineral peaks and a large variety of negative ion signals. In addition to $\mathrm{NO}_{2}^{-}$, carbon/organic fragments and sulfate also substantial amounts of lead are present. Furthermore, this is the only class where chloride $(\mathrm{m} / z 35$ and $\mathrm{m} / \mathrm{z} 37)$ can be found. This class is not present in the DR classification. It can be stated that there is a qualitative enhancement of this particle class in the IR compared to the BG aerosol even when considering the limited comparability of the two groups as stated above. This enhancement may be due to the role of lead in ice activation.

\subsection{ATOFMS results: chemical characterization for background aerosol particles, ice residues, and droplet residues}

\subsubsection{Background aerosol particles}

The background aerosol particles (BG) analyzed during CLACE 6 were grouped into 8 classes. Not all classes were required to individually group the IR and DR subsets of spectra but all were present, albeit some at low concentrations, in the background aerosol (i.e., those sampled from the total inlet over the course of CLACE 6). The classification for each group is given in Fig. 4. Classes are not meant to repeat those given for the SPLAT instrument but many are correlated. For consistency with the SPLAT data, comparable classes were numbered the same as the corresponding SPLAT classes. Further information is given in the discussion.

Class 3 exhibited large sulfate signals as negative ions, with lesser abundances of organic fragments in this and the positive. Nitrate fragments were occasionally observed, normally as $\mathrm{NO}_{2}^{-}$and $\mathrm{NO}_{3}^{-}$. Class 5 exhibited the same ions as class 3 but with potassium in the positive polarity; this is often associated with biomass burning aerosol (Hudson et al., 2004). A dual polarity spectrum of a particle of class 5 is shown in Fig. 6. Notable features include a large signal due to potassium but with a lack of other elements that would be associated with mineral dust or sea salt. Instead, organic fragments are found in both polarities and this may be indicative of material associated with the combustion process or later taken up from the gas phase. Sulfate, most pronounced in negative polarity, is most likely due to gas-phase uptake or coagulation with other particles.

Class 1 includes mass spectra with potassium, sodium, calcium, iron, aluminum, and barium, among other metals, in the positive spectra. Silicon and silicon oxides were commonly observed in negative polarity, as was chlorine. Few volatile compounds were present in this class. This class would commonly be termed mineral dust or fly ash. An example of this type is also given in Fig. 6. It is noteworthy that this class was diverse, with any combination of the aforementioned species being from the largest feature in the spectrum or not being present. Class 2 exhibited many of the same features as class 1 but included sulfate, nitrate, and organic fragments, most often as negative ions. Thus, this would be typical for mineral dust or fly ash that had taken up gas-phase species. Nitrate fragments were often found in the negative polarity. Class 10 includes the same mineral features as class 1 and 2 but with features, normally in negative polarity, due to $C_{n}$ (where $C$ is mass 12 and $n$ is an integer). This class appears to be an agglomeration of black carbon and mineral dust.

Class 8 is termed metallic. This is a diverse class composed of spectra with features due exclusively to metals. For example, several spectra had signal only due to aluminum ions in the positive or, alternately, only titanium. An example is given in Fig. 6. More information regarding this class is contained in the ice residue section. Class 9 contained features due to $C_{n}$, predominantly in negative polarity, often along with organic fragments in both the negative and positive. Class 7 predominantly exhibited fragments of nitrate (e.g., $\mathrm{NO}_{2}^{-}$and $\mathrm{NO}_{3}^{-}$).

In sampling from the total inlet most of the particles were analyzed outside clouds. The most abundant class was 5, dominated by a potassium peak that indicates an influence from biomass burning. These particles comprised almost 8 in 10 particles analyzed. This is consistent with the work of Murphy et al. (2006) who observed non-volatile materials, most commonly from combustion processes, in $60-80 \%$ of mid-tropospheric particles using single particle mass spectrometry from airborne platforms. The second most abundant class was 3, sulfates and organics with little or no potassium. The other classes made up the remaining $6 \%$ of spectra. Noteworthy is that mineral dust and fly ash with some volatile material (class 2 ) was approximately $1 \%$, about twice the abundance of mineral dust without volatiles. Black carbon was about $2 \%$ of the aerosol. This is somewhat less, by about a factor of two, than was observed during a previous CLACE campaign (Cozic et al., 2008).

One of the limitations of the ATOFMS is that some particles are sized but do not produce a mass spectrum. This is plotted in Fig. 5 for the background aerosol during the mission and the IR analyzed on 1 and 2 March. This is both due to particles that pass the sizing lasers but are missed by the desorption and ionization laser and by particles which are struck by the ablation laser but do not absorb sufficient energy to produce ions. This later process is known to be due to material properties, as described by Gallavardin et al. (2008) for mineral dusts. As previously described, this is also a function of the wavelength and intensity of the desorption and ionization laser, which is different for the SPLAT and ATOFMS. The former is using a shorter wavelength laser that more effectively produces a signal from substances that are difficult to ionize. 

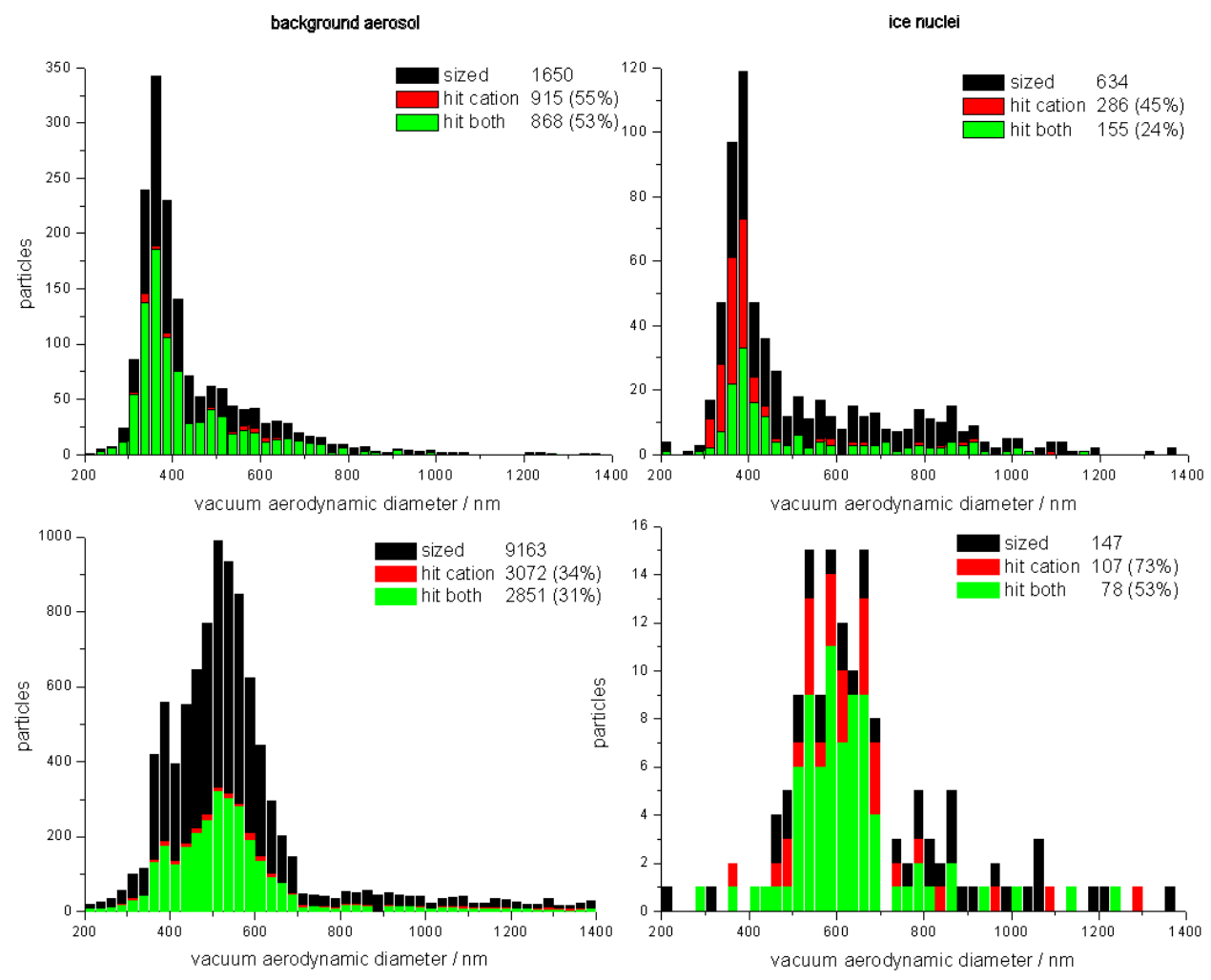

Fig. 5. Histograms for sized particles (black), particles with only a positive ion spectrum (red) and particles with both polarity spectra (green). Left: background aerosol particles; right: ice residues. Top row: SPLAT, data from 19 February for BG and from 1 March for IR; bottom row: ATOFMS, all data.

\subsubsection{Cloud ice residues}

As described in the introduction, ice nucleation in the heterogeneous regime requires the presence of a surface that enhances the formation of the solid phase (e.g., Pruppacher and Klett, 1997). As such, it is not expected that entirely aqueous particles, e.g. class 3, would act as efficient nuclei. This appears to be the case. The vast majority of ice residues fall into class 1 (31\%, mineral dust and fly ash), class $2(47 \%$, mineral dust and fly ash and some volatiles) and class 8 (14\%, metallic). Black carbon and black carbon associated with mineral dust each comprised about $2 \%$ of the ice residues. It is noteworthy that black carbon measured with Particle Soot Absorption Photometers and the ATOFMS, in addition to being more common during the previous experiment CLACE 5 , was also enhanced by a factor of about 2 in the ice phase (Cozic et al., 2008). During CLACE 6 the ATOFMS measurements revealed no obvious enhancement of $\mathrm{BC}$ in the ice phase, being $\sim 2 \%$ of the population by number in both the background and IR aerosol populations.

Two striking features are worth mentioning. First, very similar to the SPLAT results, no particles falling into class 3 (sulfates and organics) were found in the ice phase. Likewise, no particles in class 7 (nitrates) were either. Second, the predominant background class 5, associated with biomass burn- ing signatures from potassium mixed with signatures from sulfates, nitrates and organics, was extremely depleted in the ice phase. While class 5 particles made up almost $80 \%$ of the background aerosol it made up less than $2 \%$ of the IR.

\subsubsection{Cloud droplet residues}

On 6 March the Ice-CVI was used for droplet analysis. During this period spectra from just under 1100 particles were obtained. Of these, $92 \%$ were from class 3 (i.e., sulfates and organics). As for the IR there was a significant depletion of the potassium containing class 5 from $43 \%$ in the background aerosol particles on 6 March to $3 \%$ in the DR. The nitrate class 7 was observed at about $2 \%$ in the DR. Black carbon (class 9) and minerals with volatiles (class 2) were found at about their background levels. No pure mineral, metallic, or mixed mineral and BC particles were observed in the DR during this period.

\subsubsection{Comparison of classification results for BG, IR and DR}

The aerosol sampled from the total inlet during CLACE 6 fell largely into classes indicative for relatively pure sulfate and organics with some nitrate and particles with these volatiles 

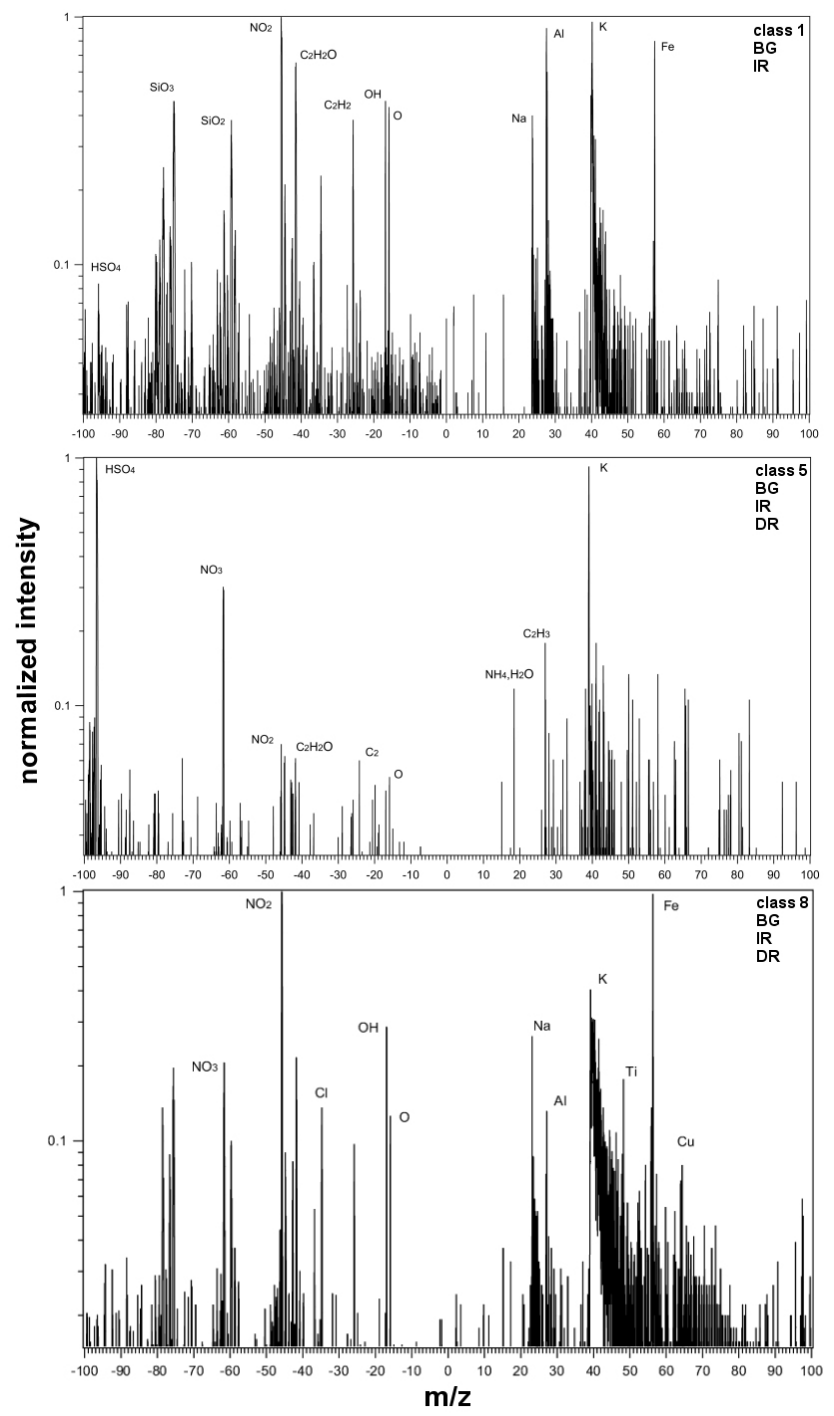

Fig. 6. Particle spectra representative of ATOFMS class 1 (mineral dust or fly ash), 5 (biomass burning) and 8 (metallic). Presence of each type in the background aerosol (BG), ice residues (IR) and droplet residues (DR) is noted.

and a biomass burning signature (potassium). Particles of mineral dust, black carbon, and a combination of these were all found at the sub-2\% level.

The DR were the most easily grouped into a single class. Over 9 in 10 DR particles fell into class 3. This is not altogether surprising. Sulfates and some organics are highly hygroscopic and readily uptake water. Note that the most populous background category, the one revealing a high fraction of potassium, which most likely is of biomass burning origin, makes up only $3 \%$ of the DR. This may be explained by the fact that biomass burning aerosol, especially before uptake of gases, is concentrated in hydrophobic materials and has been referred to as "tar balls" (Posfai et al., 2003). It is also possible that the air masses that were sampled on the day when the
DR measurements were conducted did not contain as much biomass burning aerosol components as on other days.

The IR population is more diverse but is predominantly derived from a much smaller segment of the background aerosol. Specifically, the majority of IR come from the mineral dust and fly ash, mineral dust and fly ash with volatiles, and metallic categories. This is again not unexpected. DeMott et al. (2003), for example, found mineral dust, fly ash, and metals highly enhanced in ice-forming aerosol even though these are not abundant in the background aerosol. Furthermore, biomass burning aerosol was not common in the IN analyzed by DeMott et al. (2003) although it was abundant in the background aerosol.

One issue that bears mentioning is the possibility that the metallic particles could be due to artifacts. Previous studies have shown that metallic particles can be shed when ice crystals strike inlets during aircraft flight (Murphy et al., 2004). Although the impaction of small ice particles on surfaces in the drop pre-impactor cannot be avoided for their separation from super-cooled drops, their impinging velocities are lower than for aircraft studies (Mertes et al., 2007). Empirically, neither SPLAT nor the ATOFMS spectra showed significant signatures of $\mathrm{Fe}$ and these were not accompanied by other peaks typically found for stainless steel particles (e.g., Mo, $\mathrm{Ni}$ and $\mathrm{Cr}$ ). Nevertheless, further experiments to rule out potential artifacts in the Ice-CVI are warranted.

\subsubsection{Comparison of classification results between the two instruments}

The classes used for the ATOFMS data are not directly related to those found for the SPLAT but there are noteworthy similarities. For example, bare mineral dust classes are found in both data sets (class 1 for the SPLAT and ATOFMS). Likewise, mineral dust with volatile materials is also found with both instruments (class 2 for the SPLAT and ATOFMS). Class 3 for the ATOFMS, which contains sulfates and organics and some nitrate, is a combination of SPLAT classes 3 and 4. For the ATOFMS, the ratios among sulfate, organic and nitrate fragment signals are variable and do not allow for separation into sub-classes. While the sulfate signal was commonly the most dominant in negative polarity mass spectra, the specific ratio of sulfate to organic fragment signals varied continuously such that at times they were equivalent, or even dominated by the organics. There was, therefore, no ratio that could be chosen as a logical breakpoint between sub-classes. Likewise, class 5 of the ATOFMS data, likely attributed to biomass burning, contains $\mathrm{K}^{+}$with sulfates, organics, and some nitrate fragments in variable ratios. This is equivalent to SPLAT classes 5 and 6.

For the background aerosol the data sets of the two instruments are largely in agreement when considering the differences between the classifications schemes and instrumental hardware. In addition, specifically for the total BG data substantial differences exist in the time periods when the two 
instruments were measuring. Therefore, only the 6 March BG data of the two instruments can be compared directly (Fig. 4). Most aerosol particles are composed of sulfates and organics with some nitrate and $\mathrm{K}^{+}$. Specific numerical differences are most likely attributed to the fact that the ATOFMS clusters do not account for variation in the ratios among these (i.e., sulfate to organic ratio). As classes 3 and 4 of the SPLAT data also contain significant potassium signals (see Fig. 3 and abundancy of $\mathrm{K}^{+}$in Table 1), the differences between these classes for the data from the two instruments do not represent a contradiction. A classification of the data from the two instruments using identical classification procedures would be desirable but is beyond the scope of this paper.

There is both agreement and disagreement in the IR data sets of the two instruments. Mineral dust, with and without volatiles, is common in both data sets (78\% for ATOFMS, $57 \%$ for SPLAT). Class 3, the pure secondary aerosol, is absent in the IR in the SPLAT as well as in the ATOFMS. Little biomass burning aerosol can be found in the ATOFMS data. There is a higher abundance of $\mathrm{K}^{+}$-containing aerosol in the SPLAT data (class 4 and 5). As $\mathrm{K}^{+}$is found in mineral dust as well as in biomass aerosol, it is not clear if some of this material is due to the former in the SPLAT data. Class 4 of SPLAT contains signals from $\mathrm{Ca}, \mathrm{Fe}$ and $\mathrm{Si}$ (Fig. 3), therefore it is likely that this class represents particles with an insoluble core that can act as the IN that are coated by soluble compounds like sulfate, nitrate and organics. The discrepancy between SPLAT and ATOFMS in this case warrants further field and laboratory investigations. Furthermore, some signatures from metals such as titanium or copper were found in some of the ATOFMS IR data that were not detected in the SPLAT IR spectra (class 8).

The droplet residue data are very similar for both instruments. The vast majority of both data sets indicate sulfates and organics with some nitrate accounting for $95 \%$ for the ATOFMS and $88 \%$ for the SPLAT spectra (classes 3 and 4). Mineral dust is found in a lesser abundance in both data sets. $\mathrm{K}^{+}$-containing (i.e., biomass burning) aerosol particles were strongly depleted as DR in both data sets (classes 4, 5 and 6) compared to the BG particles of 6 March. Although these classes were not as abundant in the BG aerosol on 6 March as in the BG average (Fig 4), the reduction of $\mathrm{K}^{+}$containing particles in the DR is substantial and indicates that the potassium-containing particles seem to be less $\mathrm{CCN}$ active.

For all particle categories, the different wavelength of the desorption and ionization lasers between the two instruments is important. Fragment ratios and classification would not be expected to be exactly the same between the two instruments since the SPLAT, with the shorter wavelength laser, is expected to detect substances that are difficult to ionize, such as sulfates and organics, more easily. Furthermore, even for laboratory-generated particles, single mass spectra vary in relative intensity for different mass signals from particle to particle (Hinz and Spengler, 2007). Therefore, the results presented are not quantitative. In addition to this, the power density of the ablating laser plays an important role (Johnston, 2000; Hinz and Spengler, 2007). In summary, these effects are likely to explain some of the differences observed in the chemical classification between the two instruments. With the deployment of the SPLAT and the ATOFMS during the CLACE 6 campaign, which operate with $193 \mathrm{~nm}$ and $266 \mathrm{~nm}$ ablation laser wavelength, respectively, the results obtained were similar in general, but it should be emphasized that the two instruments were basically run as complementary measurements. Even when restricting the comparison to identical short time periods as for the BG particles of 6 March only, substantial differences between the two instruments remain (Fig 4). A strict and comprehensive intercomparison of the two instruments was not intended and would have required a different measurement strategy and common calibration and classification procedures.

In Fig. 5 the size distributions for sized particles, chemically analyzed particles with only positive ion mass spectra, and for chemically analyzed particles with bipolar mass spectra are shown for the IR and the BG particles for both instruments. For the SPLAT instrument, the hit rate, which is defined as the relation of chemically analyzed particles to detected particles, is $45 \%$ for those IR resulting in only positive ion mass spectra, and $24 \%$ resulting in bipolar spectra. For the background aerosol these percentages are $55 \%$ and $53 \%$, respectively. For the ATOFMS these values are $73 \%$ for the IR resulting in only positive ion mass spectra, and 53\% resulting in bipolar spectra. For the background aerosol these percentages are $34 \%$ and $30 \%$, respectively.

This can be explained by two effects: in the IR population there are many non-spherical mineral particles causing a broader particle beam and thus a lower hit rate because many ablation laser pulses miss the particles in the broad beam. This could explain the lower hit rate of the SPLAT for the IR. In contrast, the SPLAT instrument with the lower ablation wavelength is able to detect particle types that are hard to ionize, whereas the ATOFMS does not detect, for example, pure sulfate particles efficiently. Therefore, the ATOFMS likely does not resolve a fraction of the sulfate and organic rich particles which dominate the background aerosol causing the lower hit rate for the ATOFMS background measurement. From these data this effect appears to be larger than the beam broadening effect for this instrument that also exists in the IR measurements. A discussion of this effect is presented in a review article by Murphy (2007) and references.

Almost all spectra with only positive ion signals exhibit a common pattern showing $\mathrm{C}^{+}, \mathrm{C}_{2}^{+}$and $\mathrm{C}_{3}^{+}$peaks. As shown in Fig. 5 the fraction of these spectra is substantially higher for the IR compared to the background aerosol. The origin of these carbon containing particles (organic carbon or black carbon) cannot be inferred. Laboratory measurements with polystyrene latex (PSL) particles as an organic component and soot from a discharge generator as a black carbon 
analogue both resulted in pure carbon peaks $\left(\mathrm{C}^{+}, \mathrm{C}_{2}^{+}\right.$and $\mathrm{C}_{3}^{+}$) for the positive ions. Also, in the negative ion spectra pure carbon signals dominated, but in addition, for the PSL particles signals for $\mathrm{C}_{2} \mathrm{H}_{\mathrm{x}}$ appeared. With this, a differentiation between $\mathrm{OC}$ and $\mathrm{BC}$ might be feasible but further laboratory studies on this topic with special emphasis on the fragmentation with varying laser power density need to be conducted.

\subsection{Comparison with other studies}

Our results can be compared with data from the INSPECT campaign where a single particle mass spectrometer was operated behind a continuos flow diffusion chamber (CFDC) to analyse ice nuclei at Storm Peak Laboratory, CO, USA, at $3220 \mathrm{~m}$ a.s.l. (Cziczo et al., 2003; DeMott et al., 2003; Richardson et al., 2007). In these studies, ice nuclei activated in the CFDC were dominated by $\mathrm{Si}$ and $\mathrm{SiO}$. The classification of the INSPECT ice nuclei spectra identified mineral dust and fly ash as the dominant category of the heterogeneous ice nuclei, furthermore metallic particles as well as sulfate and organic particles formed important IN particle classes (Cziczo et al., 2006; De Mott et al., 2003). TEM analysis of the fly ash/mineral dust category particles suggests that $20 \%$ are from industry, identified by their high sphericity, and the rest are from natural sources (DeMott et al., 2003). In the fly ash/mineral dust category a quarter of the particles contained measurable sulfate or organics. Both studies, INSPECT and CLACE show the importance of mineral compounds for the heterogeneous ice nucleation process, for CLACE the mineal dust and processed mineral dust group seems to be even larger than for the INSPECT data. The metallic particle class (identified by the ATOFMS in CLACE) also represents a significant class (and is enhanced compared to background particles) in both studies. The qualitative agreement between the two studies is remarkable considering the different geographic locations, different exposure to anthropogenic sources at the location and the fact that in INSPECT potential ice nuclei were sampled outside clouds while in CLACE ice particle residue from actual clouds were analyzed.

The results of the present study can also be compared with those presented by Cziczo et al. (2004) on cirrus ice residues during CRYSTAL-FACE. Note that the SPLAT and the PALMS instruments utilize ablation lasers with the same wavelength. The combination of sulfate, potassium, organics and $\mathrm{NO}^{+}$(termed as the "SKON group") forms an important particle class in both studies. Cziczo et al. (2004) found 95\% of the particles outside cirrus clouds and $88 \%$ of the interstitial aerosol belonging to the SKON group. For the SPLAT results, the corresponding group is class 3 with $47 \%$ for the background aerosol. If classes 4 and 6 which also show signals similar to the SKON group are added, the overall percentages increase to $79 \%$. In their study the authors reported a much lower value of $28 \%$ for the SKON group in cirrus ice nuclei with $8 \%$ during a dust event. For the IR in mixed phase clouds we did not find any class 3 particles in our study. But if we consider class 4 in addition, as stated above, we find $25 \%$. As the OPC measurements for particles larger $1 \mu \mathrm{m}$ and the backward trajectories did not indicate that any dust events influenced the CLACE 6 measurements directly, we have no comparative results for IR during a dust event. Nevertheless, the agreement concerning the SKON group between the two studies is noteworthy, although for the CRYSTAL-FACE data homogeneous ice nucleation might have taken place.

During the CRYSTAL-FACE campaign mineral dust/fly ash was found in $1 \%$ of the particles outside clouds and in $6 \%$ of the interstitial particles. These values increased to $44 \%$ and $64 \%$ for ice residues in general and IR during a dust event, respectively. In mixed phase clouds during CLACE 6 we detected signals for mineral dust in $57 \%$ of the IR (class 1 and 2). For the background aerosol particles this value decreased to $17 \%$. This is also in good agreement with the CRYSTAL-FACE data. Again, similar to the agreement with the INSPECT study, the agreement between CLACE and CRYSTAL-FACE for the SKON type particles and the mineral dust/fly ash classes might indicate that the enhancement of mineral dust and fly ash components in IR is a rather universal feature of ice nucleation in the free troposphere rather independent of geographic location, cloud type and altitude.

Recently, Pratt et al. (2009) studied ice particle residues in orographic ice clouds at $\sim 8 \mathrm{~km}$ altitude $\left(-31\right.$ to $\left.-34^{\circ} \mathrm{C}\right)$ over Wyoming during the fall season using aircraft-aerosol time-of-flight mass spectrometry. They found that mineral dust (especially clay minerals such as illite, montmorillonite and kaolinite) accounted for $\sim 50 \%$ and biological particles for $\sim 33 \%$ of the ice crystal residues. The biological particles were identified by characteristic signals from organic nitrogen and phosphor $m / z 42\left(\mathrm{CNO}^{-}\right), 26\left(\mathrm{CN}^{-}\right), 79\left(\mathrm{PO}_{3}^{-}\right)$ in negative ion mode and simultaneous organic and calcium markers in positive-ion mode such $m / z 12\left(\mathrm{C}^{+}\right), 24\left(\mathrm{C}_{2}^{+}\right)$, $27\left(\mathrm{C}_{2} \mathrm{H}_{3}^{+}\right), 40\left(\mathrm{Ca}^{+}\right), 56\left(\mathrm{CaO}^{+}\right)$, and others. We inspected the ice residue spectra from SPLAT and ATOFMS for these characteristic markers and found only about $2-3 \%$ of the ice residue that could be classified as biological. The presence of biological ice nuclei most likely depends strongly on the source region and season of the sampled air masses and the fraction of biological ice residues may vary greatly.

The results from our background particle measurements can also be compared to the single particle mass spectrometric measurements by LAMPAS 2 at JFJ from March 2000 reported by Hinz et al., 2005. Note that again the results are not directly comparable as these authors focused on larger particles $(95 \%$ of analyzed particles $>500 \mathrm{~nm})$ and a large fraction of their data is influenced by two Saharan dust events, which were encountered during their 10 days of measurement. Furthermore, the LAMPAS 2 instrument operates with yet another wavelength of the desorption and ionization laser of $337 \mathrm{~nm}$. Taking these differences into account, 
their particle analysis compares favourably with our results and similar classes are found for the background particles.

\section{Summary}

Two different single particle mass spectrometers were applied downstream of an Ice-CVI and a total aerosol inlet to investigate the chemical composition of residues from small ice particles, assumed to represent the original ice nuclei. To our knowledge, these are the first in situ measurements of the chemical composition of ice residues in mixed phase clouds by Single Particle Mass Spectrometry. These measurements were compared to the composition of background aerosol particles and cloud droplet residues in mixed phase clouds. The measurements were carried out at the Jungfraujoch High-Alpine Research Station in the Swiss Alps at $3580 \mathrm{~m}$ a.s.l. Although the two instruments differ in the ionization wavelength, $266 \mathrm{~nm}$ and $193 \mathrm{~nm}$, the general findings on the chemical composition agree to a large extent. Mineral dust was the dominant contributor to the composition of ice residues while it had only a low abundance in the background aerosol and the cloud droplet residues. The class of mineral dust spectra showed especially signatures from $\mathrm{Si}$, $\mathrm{SiO}, \mathrm{Al}, \mathrm{Ca}, \mathrm{CaO}$ or Fe. Sulfate showed a contrary behavior compared to mineral dust. We found a high abundance of sulfate in the background aerosol particles, much more frequently than for the ice residues. Nevertheless, many of the ice residues showed some sulfate (classes 2 and 4), indicating that either some aging and coating of the ice nuclei had taken place before activation, sulfate was produced during cloud processing in cloud droplets before freezing, or sulfate was incorporated into the cloud ice particles after activation. Furthermore, sulfate was strongly enriched in the cloud droplet residues compared to the background aerosol particles.

Due to the low concentration of ice residue particles these conclusions are drawn from measurements over a period of time in which different air masses reached the measurement site. Further improvements on the efficiency of the single particle instruments are currently under development to be able to conduct time resolved investigations of the chemical composition of ice residues and to correlate these results with meteorological measurements.

Acknowledgements. We thank Martin Gysel, Ernest Weingartner and Urs Baltensperger from PSI Villigen for cooperation and support during the CLACE experiment and for operating the total aerosol inlet. We thank Barbara Fay and Andreas Klein from the German Weather Service for providing trajectory calculations. We also thank Ulrike Lohmann for useful discussions.

We thank the International Foundation High Altitude Research Stations Jungfraujoch and Gornergrat (HFSJG) for providing the excellent infrastructure at the Jungfraujoch. Support by the project European Supersites for Atmospheric Aerosol Research (EUSAAR) and the FP6 Network Of Excellence ACCENT (access to infrastructures, field stations) is acknowledged.
Financial support for MK, for instrument development and for carrying out the CLACE 6 experiment was provided by the German Research Foundation DFG within the Collaborative Research Centre 641 "The Tropospheric Ice Phase", project A3. ME-M thanks for funding by the DFG through the Research Training Group 826 "Trace Analysis of Elemental Species". SM thanks for support by DFG grants HE 939/8-1 and 939/8-2. Internal funding by the Max Planck Institute for Chemistry for the instrument development and for the annual support of the International Foundation High Altitude Research Stations Jungfraujoch and Gornergrat (HFSJG) is gratefully acknowledged.

Edited by: E. Weingartner

\section{References}

Abbatt, J. P. D., Benz, S., Cziczo, D. J., Kanji, Z., Lohmann, U., and Möhler, O.: Solid ammonium sulfate aerosols as ice nuclei: A pathway for cirrus cloud formation, Science, 313, 1770-1773, 2006.

Borys, R. D. and Duce, R. A.: Relationships among lead, iodine, trace metals and ice nuclei in a coastal urban atmosphere. J. Appl. Meteorol., 18, 1490-1494, 1979.

Bundke, U., Nillius, B., Jaenicke, R., Wetter, T., Klein, H., and Bingemer, H.: The Fast Ice Nucleus Chamber FINCH, Atmos. Res., 90, 180-186, 2008.

Cantrell, W. and Heymsfield, A.: Production of ice in tropospheric clouds, Bull. Am. Meteor. Soc., 86, 795-807, 2005.

Canagaratna, M. R., Jayne, J. T., Jimenez, J. L.,. Allan, J. D., Alfarra, M. R., Zhang, Q., Onasch, T. B., Drewnick, F., Coe, H., Middlebrook, A., Delia, A., Williams, L. R., Trimborn, A. M., Northway, M. J., DeCarlo, P. F., Kolb, C. E., Davidovits, P., and Worsnop, D. R.: Chemical and microphysical characterization of ambient aerosols with the Aerodyne Aerosol Mass Spectrometer, Mass Spectrom. Rev., 26, 185-222, 2007.

Coen, M. C., Weingartner, E., Nyeki, S., Cozic, J., Henning, S., Verheggen, B., Gehrig, R., and Baltensperger, U.: Long-term trend analysis of aerosol variables at the high-alpine site Jungfraujoch, J. Geophys. Res., 112, doi:10.1029/2006JD007995, 2007.

Cozic, J., Verheggen, B., Mertes, S., Connolly, P., Bower, K., Petzold, A., Baltensperger, U., and Weingartner, E.: Scavenging of black carbon in mixed phase clouds at the high alpine site Jungfraujoch, Atmos. Chem. Phys., 7, 1797-1807, doi:10.5194/acp-7-1797-2007, 2007.

Cozic, J., Mertes, S., Verheggen, B., D, Cziczo, D. J., Gallavardin, S. J., Walter, S., Baltensperger, U., and Weingartner, E., Black carbon enrichment in atmospheric ice particle residuals observed in lower tropospheric mixed-phase clouds, J. Geophys. Res., 113, D15209, doi:10.1029/2007JD009266, 2008.

Cziczo, D. J., DeMott, P. J. Brock, C., Hudson, P. K., Jesse, B., Kreidenweiss, S. M., Prenni, A. J., Schreiner, J., Thomson, D. S., and Murphy, D. M.: A method for single particle mass spectrometry of ice nuclei, Aerosol Sci. Tech., 37, 460-470, 2003.

Cziczo, D. J., Murphy, D. M., Hudson, P. K., and Thomson, D. S.: Single particle measurement of the chemical composition of cirrus ice residue during CRYSTAL-FACE, J. Geophys. Res., 109, D04201, doi:10.1029/2003JD004032, 2004.

Cziczo, D. J., Thomson, D. S., Thompson, T. L., DeMott, P. J., and Murphy, D. M.: Particle analysis by laser mass spectrome- 
try (PALMS) studies of ice nuclei and other low number density particles, Int. J. Mass Spec., 258, 21-29, 2006.

Cziczo, D. J., Stetzer, O., Worringen, A., Ebert, M., Weinbruch, S., Kamphus, M., Gallavardin, S. J., Curtius, J., Borrmann, S., Froyd, K. D., Mertes, S., Möhler, O., and Lohmann, U.: Inadvertent climate modification due to anthropogenic lead, Nature Geosci., 2, 333-336, doi:101038/NGEO499, 2009.

DeMott, P. J., Cziczo, D. J., Prenni, A. J., Murphy, D. M., Kreidenweis, S. M., Thomson, D. S., Borys, R., and Rogers, D. C.: Measurements of the concentration and composition of nuclei for cirrus formation, Proc. Natl. Acad. Sci., 100, 14655-14660, 2003.

Detwiler, A. G. and Vonnegut, B.: Humidity required for ice nucleation from the vapor onto silver iodide and lead aerosols over the temperature range -6 to $-67 \mathrm{C}$, J. Appl. Meteor., 20, 10061012, 1981.

Durant, A. J. and Shaw, R. A.: Evaporation freezing by contact nucleation inside-out, Geophys. Res. Lett., 32, L20814, doi:10.1029/2005GL024175, 2005.

Ettner, M., Mitra, S. K., and Borrmann, S.: Heterogeneous freezing of single sulphuric acid solution droplets: laboratory experiments utilising an acoustic levitator, Atmos. Chem. Phys., 4, 1887-1909, doi:10.5194/acp-4-1887-2004, 2004.

Field, P. R., Möhler, O., Connolly, P., Krämer, M., Cotton, R., Heymsfield, A. J., Saathoff, H., and Schnaiter, M.: Some ice nucleation characteristics of Asian and Saharan desert dust, Atmos. Chem. Phys., 6, 2991-3006, doi:10.5194/acp-6-2991-2004, 2006.

Fusina, F., Spichtinger, P., and Lohmann, U.: Impact of ice supersaturated regions and thin cirrus on radiation in the midlatitudes, J. Geophys. Res., 112, D24S14, doi:10.1029/2007JD008449.

Gallavardin, S., Lohmann, U., and Cziczo, D. J.: Analysis and differentiation of mineral dust by single particle laser mass spectrometry, Int. J. Mass Spec., 274, 56-63, 2008.

Gard, E., Mayer, J. E., Morrical, B. D., Dienes, T., Fergenson, D. P., and Prather, K. A.: Real-time analysis of individual atmospheric aerosol particles: Design and performance of a portable ATOFMS, Anal. Chem., 69, 4083-4091, 1997.

Gross, D. S., Schauer, J. J., Chen, L., Ramakrishnan, R., Ritz, A., Smith, T., and Musicant, D. R.: Enchilada: A data-mining application for the analysis of atmospheric mass spectrometry data, Poster presentation and published abstract, International Aerosol Conference, St. Paul, MN, USA, 2006.

Herich, H., Kammermann, L.; Gysel, M., Weingartner, E., Baltensperger, U., Lohmann, U., and Cziczo, D. J.: In-situ determination of atmospheric aerosol composition as a function of hygroscopic growth, J. Geophys. Res., 113, D16213, doi:10.1029/2008JD009954, 2008.

Hinz, K.-P., Greweling, M., Drews, F., and Spengler, B.: Data processing in on-line laser mass spectrometry of inorganic, organic, or biological airborne particles, J. Am. Soc. Mass Spectrom., 10, 648-660, 1999.

Hinz, K.-P., Trimborn, A., Weingartner, E., Hennig, S., Baltensperger, U., and Spengler, B., Aerosol single particle composition at the Jungfraujoch, J. Aerosol Sci., 36, 123-145, 2005.

Hinz, K.-P. and Spengler, B.: Instrumentation, data evaluation and quantification in on-line aerosol mass spectrometry, J. Mass Spec., 42, 843-860, 2007.

Hudson, P. K., Murphy, D. M., Cziczo, D. J., Thomson, D. S., de Gouw, J. A., Warneke, C., Holloway, J., Jost, H.-J., and Hübler, G.: Biomass burning particle measurements: characteristic composition and chemical processing, J. Geophys. Res., 109, D23S27, doi:10.1029/2003JD004398, 2004.

Johnston, M. V.: Sampling and analysis of individual particles by aerosol mass spectrometry, J. Mass Spec., 35, 585-595, 2000.

Koop, T., Luo, B., Tsias, A., and Peter, T.: Water activity as the determinant for homogeneous ice nucleation in aqueous solutions, Nature, 406, 611-614, 2000.

Kamphus, M., Ettner-Mahl, M., Brands, M., Curtius, J., Drewnick, F., and Borrmann, S.: Comparison of two aerodynamic lenses as an inlet for a single particle laser ablation mass spectrometer, Aerosol Sci. Tech., 42, 970-980, 2008.

Lau, K. M. and Wu, H. T.: Warm rain processes over tropical oceans and climate implications, Geophys. Res. Lett., 30, 2290, doi:10.1029/2003GL018567, 2003.

Lin, J. C., Matsui, T., Pielke Sr., R. A., and Kummerow, C.: Effects of biomass-burning-derived aerosols on precipitation and clouds in the Amazon basin: A satellite-based empirical study, J. Geophys. Res.-Atmos., 111, D19204, doi:10.1029/2005JD006884, 2006.

Liu, P., Ziemann, P. J., Kittelson, D. B., and McMurry, P. H.: Generating particle beams of controlled dimensions and divergence: I. Theory of particle motion in aerodynamic lenses and nozzle expansions, Aerosol Sci. Technol., 22, 293-313, 1995.

Liu, P., Ziemann, P. J., Kittelson, D. B., and McMurry, P. H.: Generating particle beams of controlled dimensions and divergence: II. Experimental evaluation of particle motion in aerodynamic lenses and nozzle expansions, Aerosol Sci. Tech., 22, 314-324, 1995.

Maulik, U. and Bandyopadhyay, S.: Performance evaluation of some clustering algorithm and validity indices, ieee transactions on pattern analysis and machine intelligence, 24, 1650-1654, 2002.

Mertes, S., Schwarzenbock, A., Laj, P., Wobrock, W., Pichon, J. M., Orsi, G., and Heintzenberg, J.: Changes of cloud microphysical properties during the transition from supercooled to mixed-phase conditions during CIME, Atmos. Res., 58(4), 267-294. 2001.

Mertes, S., Verheggen, B., Walter, S., Connolly, P., Ebert, M., Schneider, J., Bower, K. N., Cozic, J., Weinbruch, S., Baltensperger, U., and Weingartner, E.: Counterflow virtual impactor based collection of small ice particles in mixed-phase clouds for the physico-chemical characterization of tropospheric ice nuclei: sampler description and first case study. Aerosol Sci. Tech., 41, 848-864, 2007.

Mierswa, I., Wurst, M., Klinkenberg, R., Scholz, M., and Euler, T.: YALE: Rapid prototyping for complex data mining tasks, in Proceedings of the 12th ACM SIGKDD International Conference on Knowledge Discovery and Data Mining (KDD-06), 2006.

Möhler, O., DeMott, P. J., Vali, G., and Levin, Z.: Microbiology and atmospheric processes: the role of biological particles in cloud physics, Biogeosciences, 4, 1059-1071, doi:10.5194/bg-4-10592007, 2007.

Murphy, D. M., Cziczo, D. J., Hudson, P. K., Thomson, D. S., Wilson, J. C., Kojima, T., and Buseck, P. R.: Particle generation and resuspension in aircraft inlets when flying in clouds, Aerosol Sci. Tech., 38, 401-409, 2004.

Murphy, D. M., Cziczo, D. J., Froyd, K. D., Hudson, P. K., Matthew, B. M., Middlebrook, A. M., Peltier, R. E., Sullivan, A., Thom- 
son, D. S., and Weber, R. J.: Single-particle mass spectrometry of tropospheric aerosol particles, J. Geophys. Res., 111, doi:10.1029/2006JD007340, 2006.

Murphy, D. M.: The design of single particle laser mass spectrometers, Mass Spec. Rev., 26, 150-165, 2007.

Ogren, J. A., Heintzenberg, J., and Charlson, R. J.: In-situ sampling of clouds with a droplet to aerosol converter. Geophys. Res. Lett., 12, 121-124, 1985.

Petters, M. D., Parsons, M. T., Prenni, A. J., DeMott, P. J., Kreidenweis, S. M., Carrico, C. M., Sullivan, A. P., McMeeking, G. R., Levin, E., Wold, C. E., Collett, J. L., and Moosmuller, H.: Ice nuclei emissions from biomass burning, J. Geophys. Res.-Atmos., 114, D07209, doi:10.1029/2008JD011532, 2009.

Pósfai, M., Simonics, R., Li, J., Hobbs, P. V., and Buseck, P. R.: Individual aerosol particles from biomass-burning in southern Africa: 1. Compositions and size distributions of carbonaceous particles, J. Geophys. Res., 108, 8483, doi:10.1029/2002JD002291, 2003.

Pratt, K. A., DeMott, P. J., French, J. R., Wang, Z., Westphal, D. L., Heymsfield, A. J., Twohy, C. H., Prenni, A. J., Prather, K. A.: In situ detection of biological particles in cloud ice-crystals, Nature Geosci., 2, 398-401, doi:10.1038/NGEO521, 2009.

Prenni, A. J., Petters, M. D., Kreidenweis, S. M., Heald, C. L., Martin, S. T., Artaxo, P., Garland, R. G., Wollny, A. G., and Poschl, U.: Relative roles of biogenic emissions and Saharan dust as ice nuclei in the Amazon basin, Nature Geosci., 2, 402405, doi:10.1038/NGEO517, 2009.

Pruppacher, H. R. and Klett, J. D.: Microphysics of Clouds and Precipitation, Kluwer Academic Publishers, Dordrecht, The Netherlands, p. 119 and p. 309, 1997.

Rebotier, P. T. and Prather, K. A.: Aerosol time-of-flight mass spectrometry data analysis: A benchmark of clustering algorithms, Anal. Chim. Acta, 585, 38-54, 2007.

Rogers, D. C., DeMott, P. J., Kreidenweis, S. M., and Chen, Y.: A continuous-flow diffusion chamber for airborne measurements of ice nuclei, J. Atmos. Oceanic Tech., 18 725-741, 2001.

Salam, A., Lohmann, U., Crenna, B., Lesins, G., Klages, P., Rogers, D., Irani, R., MacGillivray, A., and Coffin, M.: Ice nucleation studies of mineral dust particles with a new continuous flow diffusion chamber, Aerosol Sci. Tech., 40, 134-143, 2006.

Sassen, K. and Khvorostyanov, V. I.: Cloud effects from boreal forest fire smoke: Evidence for ice nucleation from polarization lidar data and cloud model simulations, Environ. Res. Lett., 3, 025006, doi:10.1088/1748-9326/1083/1082/025006, 2008.

Schaefer, V. J.: Silver and lead iodides as ice-crystal nuclei, J. Meteorol. 11, 417-419, 1954.

Schaefer, V. J., Ice nuclei from automobile exhaust and iodine vapor, Science, 154, 1555-1557, 1966.

Schoolcraft, T. A., Constable, G. S., Zhigilei, L. V., and Garrison, B. J.: Molecular dynamics simulation of the laser disintegration of aerosol particles, Anal. Chem., 72, 5143-5150, 2000.
Schreiner, J., Schild, U., Voigt, C., and Mauersberger, K.: Focusing of aerosols into a particle beam at pressures from 10 to 150 torr, Aerosol Sci. Tech., 31, 373-382, 1999.

Schwarzenböck, A., Heintzenberg, J., and Mertes, S.: Incorporation of aerosol particles between 25 and 850 nanometers into cloud elements: Measurement with a new complementary sampling system, Atmos. Res., 52, 241-260, 2000.

Stetzer, O., Baschek, B., Lüönd, F., and Lohmann, U.: The Zurich Ice Nucleation Chamber (ZINC) - A new instrument to investigate atmospheric ice formation, Aerosol Sci. Tech., 42, 64-74, 2008.

Szyrmer, W. and I. Zawadzki: Biogenic and anthropogenic sources of ice forming nuclei: A review, B. Am. Meteorol. Soc., 78(2), 209-228, 1997.

Targino, A. C., Krejci, R., Noone, K. J., and Glantz, P.: Single particle analysis of ice crystal residuals observed in orographic wave clouds over Scandinavia during INTACC experiment, Atmos. Chem. Phys., 6, 1977-1990, doi:10.5194/acp-6-1977-2006, 2006.

Thomson, D. S. and Murphy, D. M.: Laser-induced ion formation thresholds of aerosol particles in a vacuum, Appl. Optics, 32, 6818-6826, 1993.

Thomson, D. S., Middlebrook, A. M., and Murphy, D. M.: Thresholds for laser-induced ion formation from aerosols in a vacuum using ultraviolet and vacuum-ultraviolet laser wavelengths, Aerosol Sci. Technol., 26, 544-559, 1997.

Vali, G.: Repeatability and randomness in heterogeneous freezing nucleation, Atmos. Chem. Phys., 8, 5017-5031, doi:10.5194/acp-8-5017-2008, 2008.

Von Blohn, N., Mitra, S. K., Diehl, K., and Borrmann, S.: The ice nucleating ability of pollen. Part III: New laboratory studies in immersion and contact freezing modes including more pollen types, Atmos. Res., 78, 182-189, 2005.

Weingartner, E., Nyeki, S., and Baltensperger, U.: Seasonal and diurnal variation of aerosol size distributions $(10<\mathrm{d}<750 \mathrm{~nm})$ at a high-alpine site (Jungfraujoch $3580 \mathrm{~m}$ asl), J. Geophys. Res. 104(D21), 26809-26820, 1999.

Zelenyuk, A., Imre, D., Cai, Y., Mueller, K., Han, Y., and Imrich, P.: SpectraMiner, an interactive data mining and visualization software for single particle mass spectroscopy: A laboratory test case, Int. J. Mass Spec., 258, 58-73, 2006.

Zhao, W., Hopke, P. K., Qin, X., and Prather, K. A.: Predicting bulk ambient aerosol compositions from ATOFMS data with ART2a and multivariate analysis, Anal. Chim. Acta, 549, 179-187, 2005 .

Zhou, L., Hopke, P. K., and Venkatachari, P.: Cluster analysis of single particle mass spectra measured at Flushing, NY, Anal. Chim. Acta, 555, 47-56, 2006. 